\title{
Enhanced empirical models for predicting the drift capacity of less ductile RC columns with flexural, shear, or axial failure modes
}

\author{
Mohammad Reza AZADI KAKAVAND ${ }^{a^{*}}$, Reza ALLAHVIRDIZADEH ${ }^{b}$ \\ ${ }^{a}$ Unit of Strength of Materials and Structural Analysis, Institute of Basic Sciences in Engineering Sciences, University of Innsbruck, \\ Innsbruck 6020, Austria \\ ${ }^{b}$ ISISE, Department of Civil Engineering, University of Minho, Guimarães 4800-058, Portugal \\ *Corresponding author. E-mail: mohammadreza.azadi86@gmail.com
}

(C) The Author(s) 2019. This article is published with open access at link.springer.com and journal.hep.com.cn

\begin{abstract}
Capacity of components subjected to earthquake actions is still a widely interesting research topic. Hence, developing precise tools for predicting drift capacities of reinforced concrete (RC) columns is of great interest. RC columns are not only frequently constructed, but also their composite behavior makes the capacity prediction a task faced with many uncertainties. In the current article, novel empirical approaches are presented for predicting flexural, shear and axial failure modes in RC columns. To this aim, an extensive experimental database was created by collecting outcomes of previously conducted experimental tests since 1964, which are available in the literature. It serves as the basis for deriving the equations for predicting the drift capacity of RC columns by different regression analyses (both linear with different orders and nonlinear). Furthermore, fragility curves are determined for comparing the obtained results with the experimental results and with previously proposed models, like the ones of ASCE/SEI 41-13. It is demonstrated that the proposed equations predict drift capacities, which are in better agreement with experimental results than those computed by previously published models. In addition, the reliability of the proposed equations is higher from a probabilistic point of view.
\end{abstract}

KEYWORDS flexural-shear-axial failure, drift capacity, reinforced concrete columns, statistical analysis, fragility curves

\section{Introduction}

The design of RC structures involving natural hazards, especially earthquake excitations, has been significantly advanced in the past few decades, although still considerable uncertainties exist. From a general point of view, an appropriate design requires the accurate prediction of induced demands due to possible future earthquakes and providing the capacity to withstand such external actions. Since structural components vary by geometrical and mechanical properties, determination of reliable failure estimates of structural components is still a big challenge for researchers and practical engineers. Reliable failure estimates enable the designer to evaluate the local and global behavior of structures subjected to different external

Article history: Received Aug 10, 2018; Accepted Oct 8, 2018 actions. It would be important not only from design perspective for new structures, but also from assessment and strengthening point of view for existing buildings. A major percentage of existing buildings were constructed prior to novel seismic design codes being proposed. Thus, they may not present a satisfactory behavior under future possible earthquakes, which led variety of solutions to be developed or significant strengthening costs to be induced to societies annually [1].

Considering experiences from previous earthquakes, the lateral displacements are a representative indicator for the structural behavior. Among different available parameters, ranging from the local component level to the global story/ building level, the drift ratio is well-known in both research and practice. The relation between drift ratio and parameters for the component level response was investigated in several studies [2-5]. Recently, several 
numerical and experimental studies aiming at the assessment of the lateral displacement capacity and failure in reinforced concrete components and buildings have been conducted. Among all structural component types, columns are especially important due to their role in transferring loads both under gravity and lateral loadings and also due to stability issues. Hence, desired damage levels were developed based on modern equivalent static methods predicting earthquake demands [6,7]. In this regard, the current article is particularly focused on RC columns.

A variety of parameters may contribute to the capacity of a RC elements and structures [8]. For evaluating different aspects, experimental, analytical, and numerical studies have been conducted. It was shown that the transverse reinforcement ratio and initial axial loads play a significant role for the ductility of existing buildings and the influence of varying axial and lateral loading histories on the ductility was inspected [9]. For instance, experiments on ten RC columns with non-seismic detailing, subjected to different combinations of axial and cyclic loading histories, revealed the vital role of the acting axial load on the lateral displacement capacity $[10,11]$. Such studies have led to the proposal of a damage assessment criterion for distinguishing different failure modes, i.e., flexural, shear, and axial failures [12]. Witarto et al. [13] conducted an experimental study on shear behavior of four reinforced concrete columns with respect to different cyclic loading rate and Sharifi and Maghsoudi [14] experimentally studied the flexural behavior of six heavily steel reinforced beams with high-strength concrete. In addition, some numerical studies have been carried out regarding shearflexural behavior and eventually the collapse response of reinforced concrete elements and structures $[15,16]$.

Obviously, many factors contribute to the capacity of columns. These parameters are discussed in detail in the following section.

To meet all aforementioned requirements, several equations have been proposed in the literature for predicting the onset of shear failure in RC columns. Nevertheless, despite of all achieved advancements, still several shortcomings are detected which highlight the necessity of improving those relationships. For instance, some of them are computationally expensive for being applied in large-scale models [17-19]. Additionally, by some models the corresponding drift ratio of columns at shear failure may be overestimated for low [20] or high axial load levels [21]. On the other hand, some are limited to a low or moderate level of the axial load ratio up to 0.35 $[22,23]$. Moreover, it was observed that some others may misleadingly estimate the onset of shear failure for columns, although failure in the flexure-shear mode is dominant [24]. Since the proposal of the mentioned equations further extensive experimental studies have been conducted. Thus, it can be concluded that the employed databases in previous studies $[22,23,25,26]$ can be extended and thereby the quality of the equations predicting the onset of failure of RC columns can be improved. This is the aim of the present contribution.

It focuses on the identification of the ultimate lateral displacement capacity of reinforced concrete columns for the two most common types of failure, i.e., flexural, shear, and axial failure. This is achieved by collecting an extensive database of experimental tests, from the latter the most important parameters are identified and statistical regression analyses are carried out for deriving enhanced equations for predicting the drift capacity of RC columns. In this regard, special attention is given to geometrical and mechanical properties of the tested columns. In the following, the performance and reliability of the proposed equations are evaluated compared to the predictions by the ASCE/SEI 41-13 concrete provisions [27] and by conventional numerical models such as those proposed by Elwood [25]. Eventually, four short scale RC frames and a case study RC frame are presented to validate the performance of the proposed equations. It is aiming at the assessment of the performance of the proposed improved equations.

\section{Previous approaches for predicting shear/axial failure in $\mathrm{RC}$ columns}

\subsection{Lateral drift capacity corresponding to shear failure}

Modern regulations attempt to prevent non- or less-ductile failures by following the capacity-based design approaches. The general concept is proportioning components in a way to fail under ductile mode, i.e., post-pone brittle failures. However, a great portion of existing buildings have been constructed before such regulations being proposed. Thus, experience of previous earthquakes have shown occurrence of many undesirable failures. In this regard, distinguishing possible failure modes and their corresponding capacity received a great attention both in research and practice communities.

Based on empirical, experimental, and numerical studies, several models were proposed in the literature for predicting the onset of shear failure in reinforced concrete columns. These models were developed in terms of geometrical and mechanical characteristics of columns. Some of them, which predict shear failure as a function of the lateral displacement ratio, are summarized in Table 1.

The main difference between presented models in Table 1 can be stated as the employed database (i.e., number and type of columns) [20,22]. Meanwhile, some aimed to investigate the influence of material parameters (i.e., transverse reinforcement ratio, shear strength of concrete, and initial axial load) on the onset of shear failure in $\mathrm{RC}$ columns $[23,25,26]$.

In Table $1, \Delta_{\max } / L$ is the maximum drift ratio, $\rho^{\prime \prime}$ and $\rho_{1}$ are the transverse and longitudinal reinforcement ratios, 
Table 1 Proposed models in past research activities $[20,22,23,25,26]$

\begin{tabular}{|c|c|c|c|}
\hline researcher & model (drift) for shear failure & STD & $\mathrm{COV}$ \\
\hline Pujol et al. & $(1 / 100) \cdot\left(\rho^{\prime \prime} f_{\mathrm{yt}} / v\right) \cdot(a / d)$ & 1.71 & 0.42 \\
\hline Pujol et al. & $\max \left(\frac{3}{100} \cdot \frac{a}{d}\left(1-7 k_{1}\right), \frac{1}{100}\right)$ & 1.12 & 0.55 \\
\hline Kato and Ohnishi & $\left(\Delta_{\mathrm{y}}+\Delta_{\mathrm{p}}\right) / L$ & 0.84 & 0.44 \\
\hline Elwood (flexure-shear) & $\max \left(\frac{3}{100}+4 \rho^{\prime \prime}-\frac{1}{40} \frac{v}{\sqrt{f_{\mathrm{c}}^{\prime}}}-\frac{1}{40} \frac{P}{A_{\mathrm{g}} f_{\mathrm{c}}^{\prime}}, \frac{1}{100}\right)$ in MPa & 0.97 & 0.34 \\
\hline Zhu et al. & $\begin{array}{l}\text { shear: } 2.02 \rho^{\prime \prime}-0.025 \frac{s}{d}+0.013 \frac{a}{d}-0.031 \frac{P}{A_{\mathrm{g}} f_{\mathrm{c}}^{\prime}} \\
\text { flexure: } 0.049-0.042 \frac{s}{d}+0.716 \rho_{1}-0.12 \frac{\rho^{\prime \prime} f_{\mathrm{yt}}}{f_{\mathrm{c}}^{\prime}}-0.07 \frac{P}{A_{\mathrm{g}} f_{\mathrm{c}}^{\prime}}\end{array}$ & 1.03 & $\begin{array}{l}0.35 \\
0.27\end{array}$ \\
\hline
\end{tabular}

respectively, $f_{\mathrm{c}}^{\prime}$ and $f_{\mathrm{yt}}$ are the concrete compressive strength and the yield strength of the transverse reinforcement, respectively, $v$ is the nominal shear stress, $a$ is the distance from the maximum moment to the inflection point, $d$ is the effective depth, $k_{1}$ is a coefficient dependent on the maximum drift capacity, $\Delta_{\mathrm{y}} / L$ is the drift ratio at yielding of the longitudinal reinforcement and $\Delta_{\mathrm{p}} / L$ is the plastic drift capacity, $P$ is the axial load and $A_{\mathrm{g}}$ is the gross cross-sectional area, $s$ is the spacing of the transverse reinforcement.

\subsection{Lateral drift capacity corresponding to axial failure}

Mostly, axial failure in RC columns occurs after shear failure. For this case some equations, based on a similar approach as in the previous subsection, were recommended in the literature.

One of the most popular methods was proposed by Elwood, relating axial failure in $\mathrm{RC}$ columns to the corresponding lateral displacement ratio [25]. It is based on an experimental database for existing columns characterized by the flexure-shear-axial (FSA) failure mode. Generally, existing columns are vulnerable against lateral excitations due to non-seismic detailing, which results in occurrence of shear failure followed by axial failure and consequently the collapse of column. In other words, failure of the respective column is initiated by flexural failure and ends with axial failure. Its key parameters are the axial load ratio, the shear strength of stirrups and the critical angle with respect to the horizontal plane. According to this model, the drift ratio at axial failure is given as Eq. (1):

$$
\left(\frac{\Delta}{L}\right)_{\text {axial }}=\frac{4}{100} \frac{1+\tan ^{2} \theta}{\tan \theta+P\left(s / A_{\mathrm{st}} f_{\mathrm{yt}} d_{\mathrm{c}} \tan \theta\right)},
$$

with $\theta$ as the critical crack angle from the horizontal plane, assumed as $65^{\circ}, A_{\text {st }}$ representing the cross sectional area of the transverse reinforcement and $d_{\mathrm{c}}$ as the effective depth of the column section.

Recently, other approaches, like an energy-based one, were developed for predicting axial failure. For instance, Tran and $\mathrm{Li}$ [28] consider lateral displacements due to both sliding and yielding.

\section{Proposal of a new model for flexural/shear/axial failure modes}

\subsection{Creation of an extensive database}

In this study, first of all an extensive database on experimental results from tests on RC columns for detecting flexural/shear/axial failure is collected from tests available in the literature. It should be noted that the drift ratios at flexural, shear, and axial failure were taken from the test reports. This database is provided in the Supplementary material. It forms the basis for the subsequent proposal of empirical models for predicting failure of RC columns. These models will be a function of geometrical and mechanical properties. The employed parameters, together with the respective statistical distribution, comprising the range (minimum and maximum), mean value and standard deviation, are reported for each failure type in Table 2. Additionally, the maximum drift ratios from the respective test reports are presented together with the computed statistical distributions.

Generally speaking, shear failure in RC columns can be categorized into two individual modes: flexure-shear and shear. The flexural failure and the shear failure with shear mode are identified as the most and least ductile failure mode, respectively. Traditionally, the expected behavior of columns is classified based on the ratio of plastic shear to nominal shear $\left(V_{\mathrm{p}} / V_{\mathrm{n}}\right)$. This approach is widely recommended in other regulations such as ASCE/SEI 41-13 [27]. The collected experimental results for flexural and shear failure in terms of the drift ratio are illustrated in Fig. 1(a). Note that the failure mode and corresponding drift ratio are extracted from observed experimental outcomes; however 
the ratio $V_{\mathrm{p}} / V_{\mathrm{n}}$ is calculated. It can be seen that columns characterized by $V_{\mathrm{p}} / V_{\mathrm{n}} \leqslant 0.6$ experience the flexural failure mode, while the shear failure mode controls the behavior of columns with $V_{\mathrm{p}} / V_{\mathrm{n}}>1.0$ [27].

Summarizing, the collected database can be sorted according to the mentioned ranges of $V_{\mathrm{p}} / V_{\mathrm{n}}$ in Eq. (2) as:

$$
\begin{gathered}
\left\{\frac{V_{\mathrm{p}}}{V_{\mathrm{n}}} \leqslant 0.6 \rightarrow\right. \text { flexure mode, } \\
0.6<\frac{V_{\mathrm{p}}}{V_{\mathrm{n}}} \leqslant 1.0 \rightarrow \text { flexure-shear mode },
\end{gathered}
$$

$$
\frac{V_{\mathrm{p}}}{V_{\mathrm{n}}}>1.0 \rightarrow \text { shear mode. }
$$

It is evident from Fig. 1(a) that the majority of the tested columns, included in the collected database, failed in the flexure-shear or shear failure mode. The numbers of respective tests are provided in Table 3.

Moreover, the collected experimental results for axial failure in terms of the drift ratio are depicted in Fig. 1(b) and the numbers of the respective tests are also provided in Table 3. In Table 3, 46\% and 52\% of experimental results refer to failure in the flexure-shear and shear mode, respectively, and the remaining to failure in the flexure

\begin{tabular}{|c|c|c|c|c|c|c|c|c|c|}
\hline \multirow{2}{*}{$\begin{array}{l}\text { parameter } \\
\text { (unit) }\end{array}$} & \multicolumn{3}{|c|}{ flexural failure } & \multicolumn{3}{|c|}{ shear failure } & \multicolumn{3}{|c|}{ axial failure } \\
\hline & range & mean & STD & range & mean & STD & range & mean & STD \\
\hline$\overline{\rho^{\prime \prime}(\%)}$ & [0.18-2.55] & 0.77 & 0.51 & [0.07-0.93] & 0.31 & 0.22 & {$[0.07-0.57]$} & 0.16 & 0.11 \\
\hline$\rho_{\mathrm{l}}(\%)$ & [1.27-3.28] & 2.03 & 0.50 & {$[0.56-4.00]$} & 2.17 & 0.60 & {$[0.56-3.00]$} & 2.11 & 0.59 \\
\hline a/d (-) & [1.18-6.64] & 4.10 & 1.69 & [1.18-5.40] & 2.84 & 0.99 & [1.18-4.44] & 2.48 & 1.05 \\
\hline$s / d(-)$ & {$[0.11-0.73]$} & 0.36 & 0.14 & [0.11-1.20] & 0.49 & 0.30 & {$[0.20-1.20]$} & 0.72 & 0.33 \\
\hline$f_{\mathrm{c}}^{\prime}(\mathrm{MPa})$ & [21.1-48.3] & 33.0 & 6.44 & [13.1-46.5] & 26.8 & 7.5 & [13.5-33.1] & 23.8 & 5.6 \\
\hline$f_{\mathrm{yt}}(\mathrm{MPa})$ & [308-621] & 494 & 106 & [249-648] & 410 & 78 & [289-587] & 405 & 64 \\
\hline$f_{\mathrm{yl}}(\mathrm{MPa})$ & [341-579] & 439 & 80 & [318-538] & 424 & 61 & [331-538] & 410 & 66 \\
\hline$V_{\mathrm{p}} / V_{\mathrm{n}}(-)$ & {$[0.32-0.60]$} & 0.49 & 0.07 & [0.60-2.05] & 1.03 & 0.29 & [0.52-1.57] & 0.99 & 0.23 \\
\hline$P / A_{\mathrm{g}} \cdot f_{\mathrm{c}}^{\prime}(-)$ & {$[0-0.80]$} & 0.30 & 0.22 & {$[0-0.62]$} & 0.19 & 0.14 & {$[0.04-0.62]$} & 0.23 & 0.14 \\
\hline$\Delta_{\max } / L(\%)$ & {$[0.27-7.40]$} & 3.35 & 2.06 & [0.38-9.00] & 2.80 & 2.10 & {$[0.40-8.70]$} & 3.20 & 2.00 \\
\hline
\end{tabular}
mode.

Table 2 Statistical properties of the extracted parameters from the database [29-72]

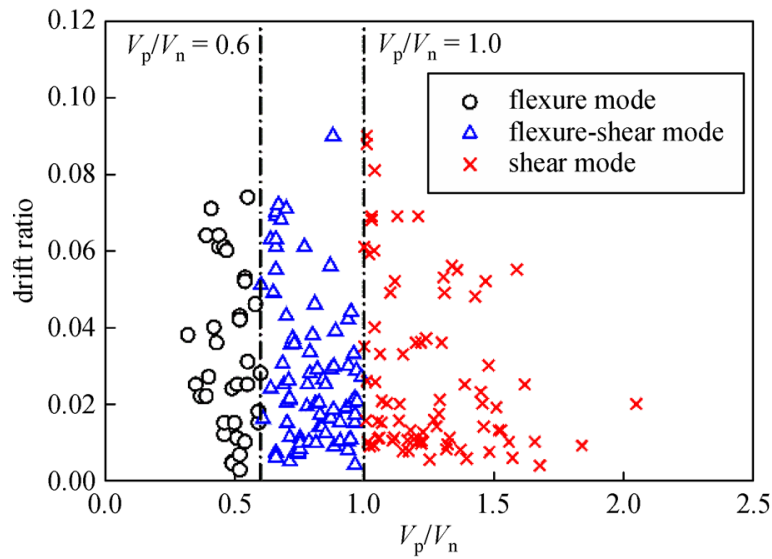

(a)

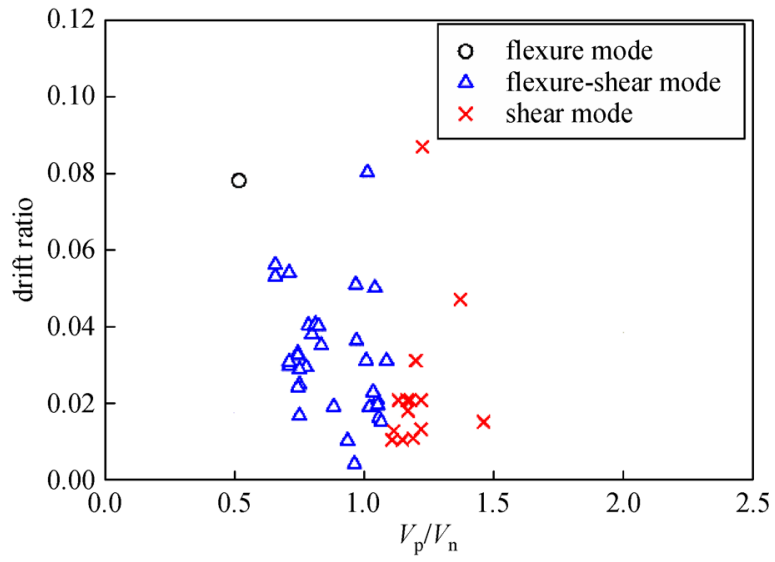

(b)

Fig. 1 Distribution of collected experimental results, classified by the respective failure mode. (a) Flexural and shear failure; (b) axial failure.

Table 3 Categorization of experimental results contained in the database

\begin{tabular}{lcccc}
\hline model & number of exp. results & flexure & flexure-shear & shear \\
flexural and shear failure & 196 & 37 & 80 & 79 \\
axial failure & 50 & 1 & 23 & 26 \\
\hline
\end{tabular}


It is worthwhile to mention that some experimental results have not been included in the database because of inconsistently imposed lateral cyclic load patterns, like in the experiments by Pujol [73]. Hence, it is assumed that they do not represent the real lateral displacement capacity [26].

In addition to classifying collected database with respect to the $V_{\mathrm{p}} / V_{\mathrm{n}}$ ratio, the distribution of other possibly contributing parameters are also taken into account. These parameters are judged (extracted) considering previously proposed models and also those parameters which were assumed to affect seismic response of a component. Scatter plot of experimentally measured drift ratios with respect to these parameters and classified based on failure modes are presented in Fig. 2.

3.2 Proposed models for the drift ratio corresponding to flexural and shear failure

The database, described in the previous subsection, is used for developing the empirical model for flexural and shear failure. For this purpose, 196 experimental results on RC columns are adopted. The respective experiments were conducted since 1964 [29-72]. To identify the main parameters for geometrical and mechanical properties, the
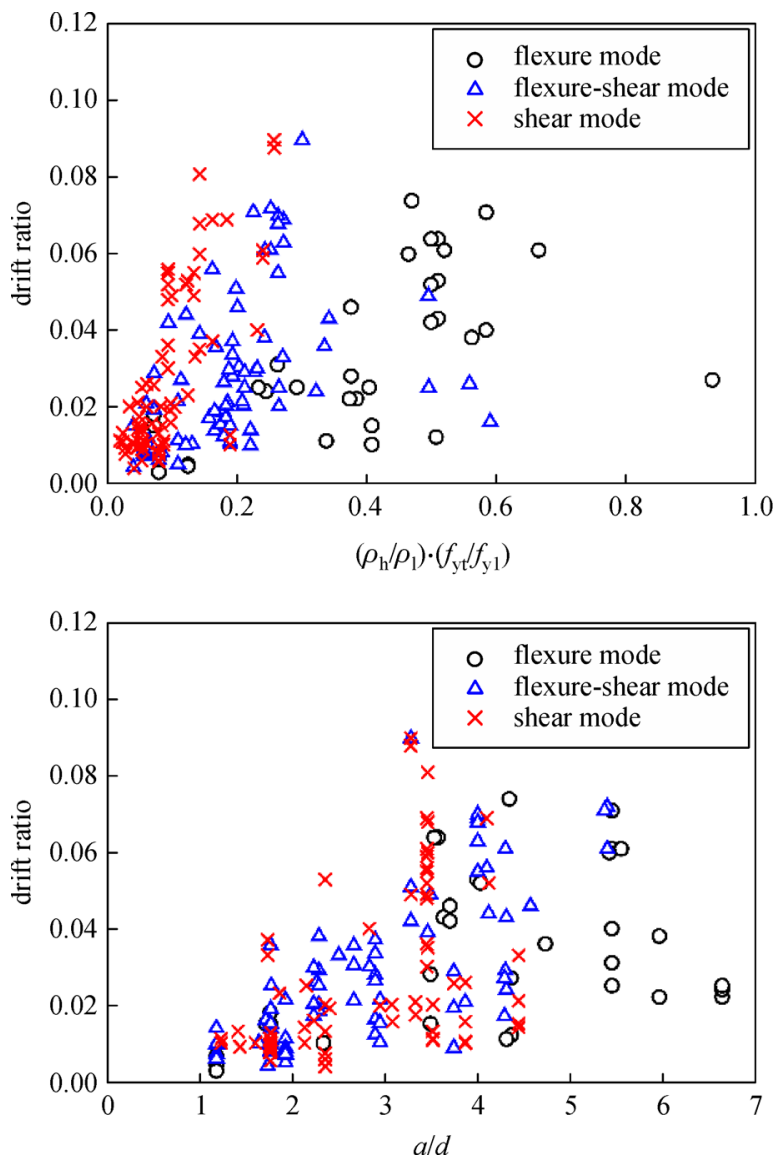

previously proposed models, listed in Table 1, were investigated in detail. In order to propose a reliable model, a variety of regression analyses including linear, second order nonlinear (quadratic without mixed terms and full quadratic equations) and nonparametric ones were conducted. Parametric regression analyses resulted in polynomial relationships for the drift capacity of a $\mathrm{RC}$ column in terms of the geometrical and mechanical parameters as generally expressed in Eq. (3):

$$
\begin{gathered}
\frac{\Delta_{\max }}{L}=\alpha_{0}+\sum_{i=1}^{n}\left(\alpha_{i} X_{i}+\alpha_{i i} X_{i}^{2}\right) \\
+\sum_{i=1}^{n} \sum_{j=1}^{n} \alpha_{i j} X_{i} X_{j}, \\
X_{1}=\left(\frac{\rho_{\mathrm{h}} f_{\mathrm{yt}}}{\rho_{1} f_{\mathrm{yl}}}\right), X_{2}=\left(\frac{P}{A_{\mathrm{g}} f_{\mathrm{c}}}\right), X_{3}=\left(\frac{V_{\mathrm{p}}}{V_{\mathrm{n}}}\right), \\
X_{4}=\left(\frac{a}{d}\right), X_{5}=\left(\frac{s}{d}\right)
\end{gathered}
$$

with $\alpha_{i}, \alpha_{i i}$, and $\alpha_{i j}$ denoting the regression coefficients and $X_{i}$ and $X_{j}$ denoting the model parameters. It should be noted that the linear relationship would be formed by substituting $\alpha_{i i}=\alpha_{i j}=0$. Additionally, the quadratic
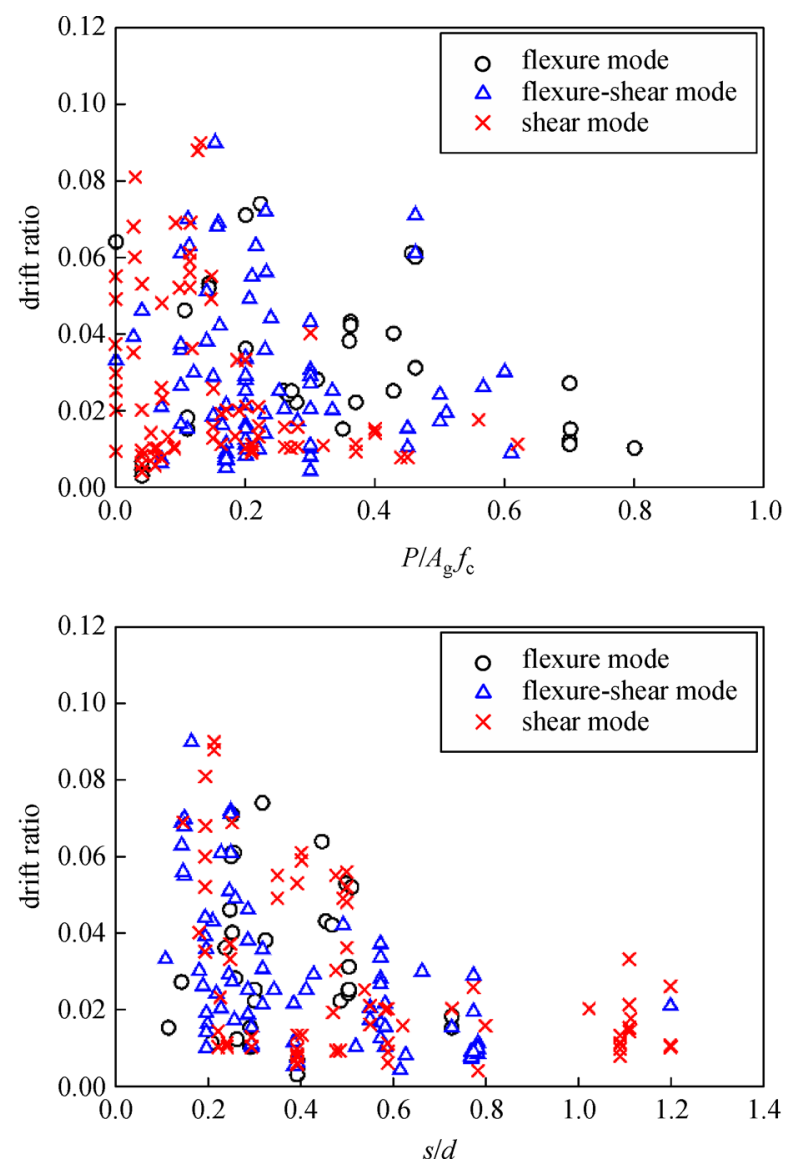

Fig. 2 Scatter plots of the drift ratio at shear failure versus the employed parameters. 
equation without mixed terms requires replacing $\alpha_{i j}=0$. Note that the parameters $\rho^{\prime \prime}$ and $\rho_{1}$ are inserted into Eq. (3) and the following equations as decimal numbers and not as percentages.

In order to determine the introduced coefficients, linear and nonlinear regression analyses are performed for each failure mode by the SPSS and Matlab software packages [74,75]. The results for the respective regression coefficients together with the standard error and the coefficient of determination $R^{2}$, ranging from 0 (no correlation) to 1 (best correlation) are summarized for the three considered failure modes in Tables 4-6.

It is worthwhile to note that the collected database in each case is randomly divided into two groups, i.e., training set and test set [76]. The former includes $70 \%$ of database (corresponding to each failure mode) and is used to propose the models. The remained $30 \%$ forms the test set, which is later employed to evaluate accuracy of proposed model for unseen data. It should be noted that reported standard error in following tables correspond to the test set. Considering higher orders may lead to equations better fitting training set (the set used for supervising the model); while it increases the possibility of over-fitting. In other words, higher order (more complex) relationships may perfectly work for training set; however may misleadingly predict unseen data. This possibility was also evaluated by means of standard test set error.

On the other hand, several advanced nonparametric regression methods are also developed in addition to the discussed parametric ones, the examples related to the latter approach is well described in [77,78]. For instance, Gaussian process (Kriging), smoothing splines, kernel and decision tree methods are some of them. In spite of parametric methods, the conditional expectation function is unknown in nonparametric ones. Thus, the predicting function would not be assumed in their procedure. Application of latter approach is well discussed in Refs. [79-83]; however their implementation in practical engineering calculations would be cumbersome. Nevertheless, the Kriging regression is conducted for the flexure failure mode; which its test set resulted in a mean absolute error equal to $0.32 \%$. However, the main objective of the current article is to propose straightforward applicable equations to be employed in practical calculations; thus nonparametric approaches are neglected in the following.

It should be noted that the followed procedure for each type of regression analysis was an iterative process; which started by considering all parameters (denoted in Eq. (3)) and repeated by neglecting less affective parameters. Contribution of parameters (possibility of being a good predictor) is controlled by checking the significance factor (Sig factor) or P-value. Parameters, characterized by a Sig factor $>0.050$, are eliminated and, hence, their corresponding coefficient is not reported in the respective table.

Aforementioned procedure for flexural failure mode is presented in Table 4. As it can be seen, the linear regression results in an equation with an $R^{2}$ of about 0.49 ; which seems not to be an acceptable match. Among all methods, the quadratic equation without mixed terms led to an acceptable $R^{2}$ (greater than 0.8) and test set error (about $1.28 \%$ ). Hence, it is proposed as Eq. (4) for further investigations. It is worthwhile to note that the quadratic equation with mix terms over-fits the training set.

$$
\begin{aligned}
\left(\frac{\Delta_{\max }}{L}\right)_{\text {Flexure }}= & -0.237+0.152\left(\frac{\rho_{\mathrm{h}} f_{\mathrm{yt}}}{\rho_{1} f_{\mathrm{yl}}}\right)-0.06\left(\frac{P}{A_{\mathrm{g}} f_{\mathrm{c}}}\right) \\
& +0.846\left(\frac{V_{\mathrm{p}}}{V_{\mathrm{n}}}\right)+0.02\left(\frac{a}{d}\right)-0.11\left(\frac{\rho_{\mathrm{h}} f_{\mathrm{yt}}}{\rho_{1} f_{\mathrm{yl}}}\right)^{2}
\end{aligned}
$$

\begin{tabular}{|c|c|}
\hline method & coefficient \\
\hline linear regression & $\begin{array}{c}\alpha_{0}=-0.044, \alpha_{1}=0.031, \alpha_{2}=-0.04, \alpha_{3}=0.096, \alpha_{4}=0.007 \\
R^{2}=0.490 \\
\text { test set error }=1.81 \%\end{array}$ \\
\hline quadratic equation (without mixed terms) & $\begin{array}{c}\alpha_{0}=-0.237, \alpha_{1}=0.152, \alpha_{2}=-0.06, \alpha_{3}=0.846, \alpha_{4}=0.02, \\
\alpha_{11}=-0.11, \alpha_{33}=-0.85, \alpha_{44}=-0.002 \\
R^{2}=0.828 \\
\text { test set error }=1.28 \%\end{array}$ \\
\hline
\end{tabular}

Table 4 Statistical data of the parameters for the flexural failure predicted by Eq. (3)

full quadratic equation

$$
\begin{gathered}
\alpha_{0}=-2.294, \alpha_{1}=1.005, \alpha_{2}=0.613, \alpha_{3}=3.255, \alpha_{4}=0.239, \\
\alpha_{5}=4.181, \alpha_{11}=-0.29, \alpha_{33}=-2.076, \alpha_{44}=-0.007, \alpha_{12}=-0.336, \\
\alpha_{13}=0.493, \alpha_{14}=-0.010, \alpha_{15}=-2.80, \alpha_{23}=-0.373, \alpha_{24}=-0.071, \\
\alpha_{25}=-0.248, \alpha_{34}=-0.057, \alpha_{35}=-2.81, \alpha_{45}=-0.334 \\
R^{2}=0.996 \\
\text { test set error }=24.86 \% \\
R^{2}=0.99
\end{gathered}
$$




$$
-0.85\left(\frac{V_{\mathrm{p}}}{V_{\mathrm{n}}}\right)^{2}-0.002\left(\frac{a}{d}\right)^{2}
$$

An identical procedure is followed for the flexure-shear and shear failure modes. However, for the sake of brevity only outcomes of the linear regression and the quadratic equation without mixed terms are reported here (see Tables 5 and 6). Similarly, the quadratic equation without mixed terms resulted promising relationships, reported as Eqs. (5) and (6):

$$
\begin{aligned}
\left(\frac{\Delta_{\max }}{L}\right)_{\text {Flex-shear }}= & 0.15+0.15\left(\frac{\rho_{\mathrm{h}} f_{\mathrm{yt}}}{\rho_{\mathrm{l}} f_{\mathrm{yl}}}\right)-0.029\left(\frac{P}{A_{\mathrm{g}} f_{\mathrm{c}}}\right) \\
& -0.354\left(\frac{V_{\mathrm{p}}}{V_{\mathrm{n}}}\right)-0.16\left(\frac{\rho_{\mathrm{h}} f_{\mathrm{yt}}}{\rho_{\mathrm{l}} f_{\mathrm{yl}}}\right)^{2} \\
& +0.202\left(\frac{V_{\mathrm{p}}}{V_{\mathrm{n}}}\right)^{2}+0.0016\left(\frac{a}{d}\right)^{2}, \\
\left(\frac{\Delta_{\max }}{L}\right)_{\text {shear }}= & -0.0117+0.0348\left(\frac{a}{d}\right)-0.078\left(\frac{s}{d}\right) \\
& +0.588\left(\frac{\rho_{\mathrm{h}} f_{\mathrm{yt}}}{\rho_{1} f_{\mathrm{yl}}}\right)^{2}-0.0042\left(\frac{a}{d}\right)^{2} \\
& +0.0385\left(\frac{s}{d}\right)^{2},
\end{aligned}
$$

3.3 Proposed model for the drift ratio corresponding to axial failure

It was shown that the drift ratio corresponding to axial failure depends on the effective coefficient of friction [25]. The latter parameter can be computed by means of a free body diagram of a column after shear failure initiation [25] as Eq. (7):

$$
\mu_{\mathrm{m}}=\frac{P-V_{\mathrm{s}}}{(P / \tan \theta)+V_{\mathrm{s}} \tan \theta}
$$

with $P$ denoting the compressive axial load acting in the column, $V_{\mathrm{s}}$ is the shear strength, depending on the transverse reinforcement and $\theta$ is the critical angle of the crack propagating due to shear failure. The latter is recommended by Kim and Mander [84] in the range of $65^{\circ}$ to $71^{\circ}$.

In order to derive an equation for predicting the effective coefficient of friction in terms of the drift ratio at axial failure a variety of functional relationships is assumed and linear regression analyses are performed to find the one with the best fit. The considered functional relationships are summarized in Table 7 together with the respective coefficient of determination $R^{2}$. It follows from Table 7 that the exponential function is a good choice.

Eventually, the relationship between the effective coefficient of friction and the drift ratio at axial failure takes the form:

$$
\mu_{\mathrm{m}}=2.1623 \mathrm{e}^{-21.4\left(\frac{\Delta_{\max }}{L}\right)_{\text {axial }} .}
$$

Table 5 Statistical data of the parameters for flexural-shear failure mode predicted by Eq. (3)

\begin{tabular}{lc}
\hline method & coefficient \\
\hline linear regression & $\alpha_{0}=0.0199, \alpha_{1}=0.05, \alpha_{2}=-0.034, \alpha_{3}=-0.025$, \\
$\alpha_{4}=0.011, \alpha_{5}=-0.013$ \\
$R^{2}=0.817$ \\
test set error $=1.45 \%$ \\
quadratic equation (without mixed terms) \\
$\alpha_{0}=0.15, \alpha_{1}=0.15, \alpha_{2}=-0.029, \alpha_{3}=-0.354, \alpha_{11}=-0.16, \alpha_{33}=0.202, \alpha_{44}=0.002$ \\
$R^{2}=0.833$ \\
test set error $=1.53 \%$
\end{tabular}

Table 6 Statistical data of the parameters for shear failure mode predicted by Eq. (3)

\begin{tabular}{lc}
\hline method & coefficient \\
\hline linear regression & $\alpha_{0}=-0.0087, \alpha_{1}=0.202, \alpha_{4}=0.0103, \alpha_{5}=-0.0186$ \\
$R^{2}=0.745$ & test set error $=1.35 \%$ \\
quadratic equation (without mixed terms) & $\alpha_{0}=-0.012, \alpha_{4}=0.0348, \alpha_{5}=-0.078, \alpha_{11}=0.588, \alpha_{44}=-0.0042, \alpha_{55}=0.0385$ \\
& $R^{2}=0.777$ \\
& test set error $=1.46 \%$ \\
\hline
\end{tabular}


Table 7 Evaluation of different functional relationships for predicting the effective coefficient of friction

\begin{tabular}{lc}
\hline type of equation & $R^{2}$ \\
\hline linear & 0.7316 \\
polynomial order 2 & 0.8020 \\
polynomial order 3 & 0.8039 \\
polynomial order 4 & 0.8310 \\
logarithmic & 0.7309 \\
power & 0.7027 \\
exponential & 0.8089 \\
\hline
\end{tabular}

By considering the critical crack angle $\theta=65^{\circ}$ and substituting Eq. (7) into Eq. (8), the equation for predicting the drift ratio corresponding to axial failure is obtained as Eq. (9):

$$
\left(\frac{\Delta_{\max }}{L}\right)_{\text {axial }}=\frac{1}{21.4} \ln \left(\frac{1+\left(V_{\mathrm{s}} / P\right) \tan ^{2} \theta}{1-\left(V_{\mathrm{s}} / P\right)}\right) .
$$

This equation identifies the onset of axial failure in reinforced concrete columns in terms of the shear strength $V_{\mathrm{s}}$, depending on the transverse reinforcement ratio, and the axial load $P$. Note that previous studies also revealed a minor influence of the longitudinal reinforcement ratio on the drift capacity corresponding to the axial failure mode [25].

\section{Accuracy evaluation of the proposed models}

In this section, the accuracy of the proposed models is evaluated for each type of failure and they are compared with the accuracy of the models, proposed by Elwood [25], Zhu et al. [26] and the ASCE/SEI 41-13 regulation [27].

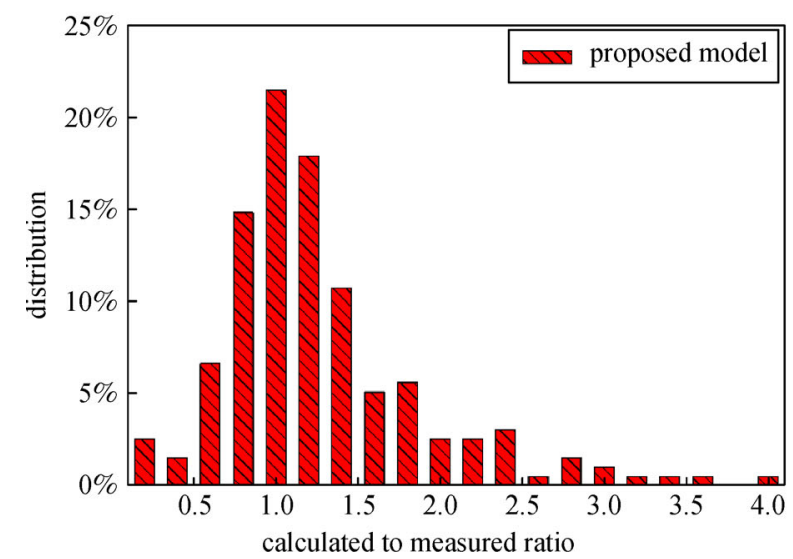

(a)
For this purpose, the ratio of the calculated drift capacity to the corresponding experimental value is determined. Whereas the former is calculated by the different models, the latter represents the measured capacity of the RC columns available in the database.

\subsection{Evaluation of flexural and shear failure models}

In order to evaluate the accuracy of the proposed equations, the drift capacities are determined for the three failure modes (flexure, flexure-shear and shear). They are calculated as the ratios of the predicted drift capacities on the basis of Eqs. (4)-(6) to the drift capacities measured in the 196 experimental tests included in the collected database and they are depicted in Fig. 3(a). Furthermore, they are compared with the respective predictions by model of Elwood and Zhu et al. (Fig. 3(b)). According to Fig. 3(b), considerable scatter of the respective ratios is observed; however, Fig. 3(a) shows for the proposed model a distribution of these ratios with a pronounced peak in the vicinity of unity. The latter property is a measure for the accuracy of the model, since the predicted drift capacities are closer to experimental results. Moreover, the models proposed by Elwood [25] model and Zhu et al. [26] result in a greater portion of predicted drift capacities, which are characterized by ratios larger than unity and, thus, overestimate the measured drift capacity. The respective probabilities will be investigated in detail in the following section.

\subsection{Evaluation of the axial failure models}

The same approach as in the previous subsection is employed for the evaluation of the axial failure models according to Elwood [25] and the present proposal. The respective diagrams are depicted in Fig. 4. Again, superior performance of the proposed model can be observed.

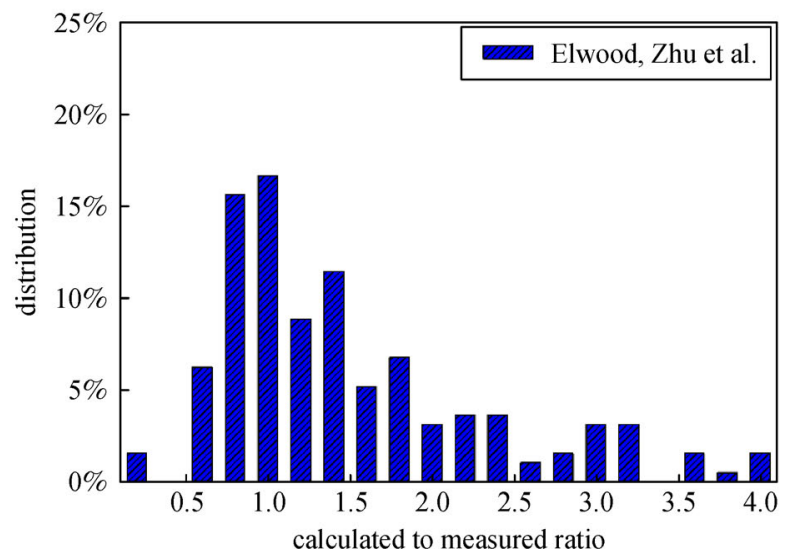

(b)

Fig. 3 Distributions of the ratio of calculated to measured drift capacity of RC columns according to (a) the proposed model for flexural, flexure-shear and shear failure modes and (b) Elwood model for flexure-shear failure mode [25] and Zhu et al. models for flexure and shear failure modes [26]. 


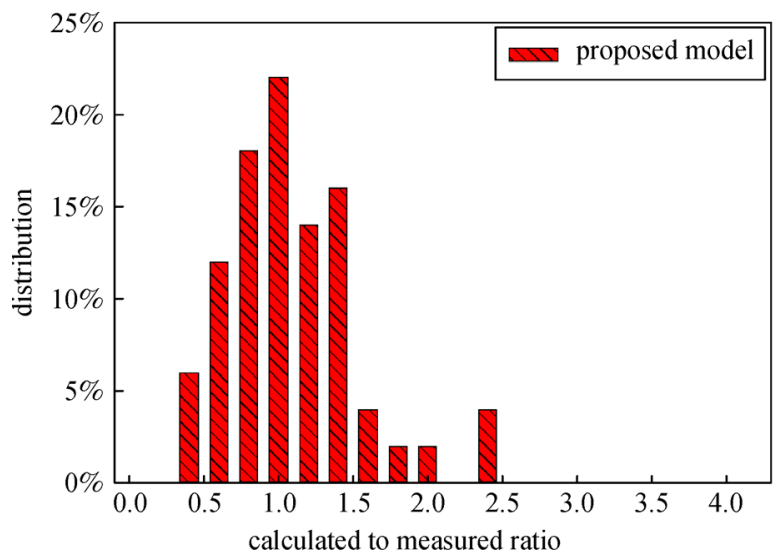

(a)

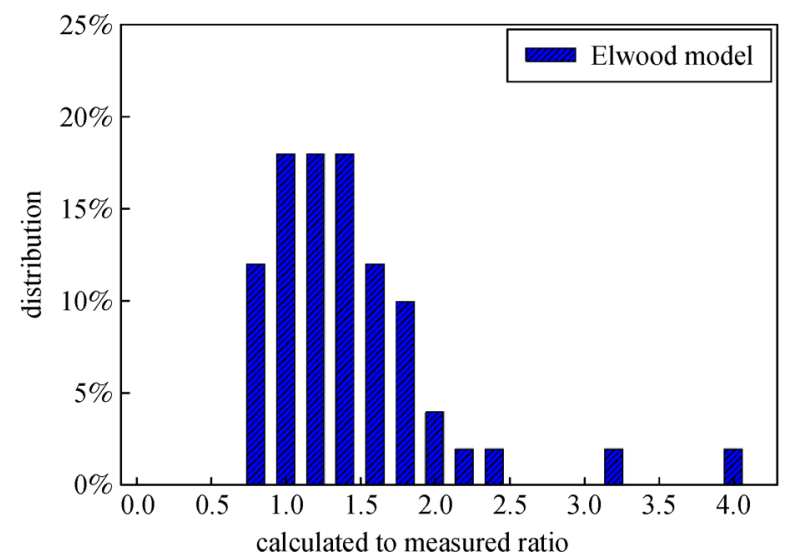

(b)

Fig. 4 Distributions of the ratio of calculated to measured drift capacity of RC columns with axial failure. (a) Proposed model; (b) Elwood model.

\section{Probabilistic assessment of the proposed method and comparison with previously proposed methods}

In this section, the fragility assessment theory is employed for comparing the results from the proposed equations with the experimental ones and those, predicted by means of conventional techniques, i.e., the ASCE/SEI 41-13 regulation [27], Elwood model [25] and model of Zhu et al. [26]. For each case, the fragility curves will be plotted, representing the probability of occurrence of flexural/shear/axial failure in terms of the drift ratio. Thereby, the drift ratio is assumed to obey the log-normal probability distribution. This assumption is validated by employing the probability paper concept, cf., e.g., Ref. [85] for the principles of this concept. In Fig. 5, the horizontal axis represents the log-normal of experimentally observed drift ratios, expressed as percentages, for the total

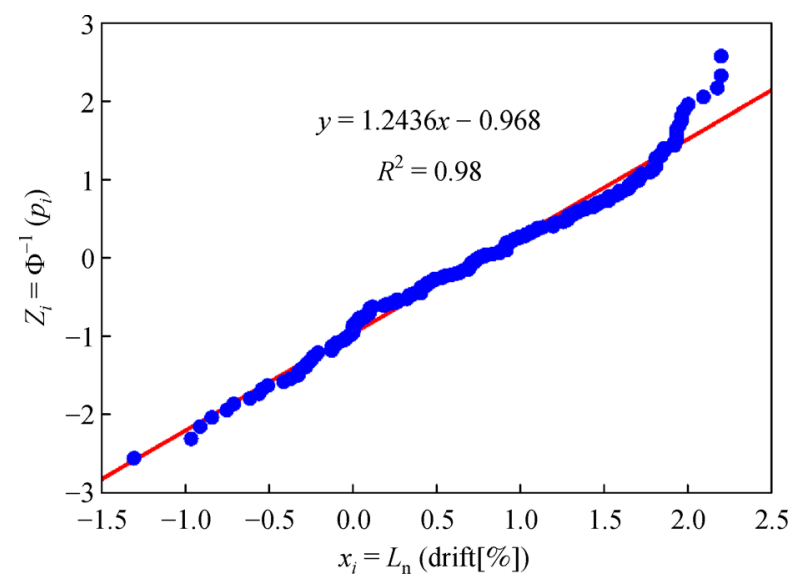

Fig. 5 Probability paper to validate log-normal probability distribution of experimentally determined drift capacities with flexural and shear failure. number of 196 columns included in the database, characterized by flexural and shear failure, while the vertical axis indicates their inverse standard log-normal distribution. The subscript $i$ corresponds to each observed data at their ascending sorted complex (from the smallest drift ratio to the largest one).

It is evident from Fig. 5 that a linear regression analysis, resulting in the coefficient of determination of $R^{2}=0.98$, fits the transformed data in log-normal coordinates very well. Thus, the assumed probability distribution is appropriate.

The respective fragility curves are depicted in Fig. 6 . They represent the probability of failure at a given drift ratio of RC columns for the three failure modes considered by the proposed Eqs. (5), (6), and (9).

In particular, the fragility curves, computed on the basis of the proposed equations [86], are compared with those from the experimental results of the tests included in the database and with the fragility curves computed on the basis of Elwood model [25], model of Zhu et al. [26], and the ASCE/SEI 41-13 regulation (using modelling parameters $a$ and $b$ ) [27]. From Fig. 6 follows quite good agreement of the fragility curves, computed on the basis of the proposed equations, with the experimental ones.

A comparative investigation of the drift ratios, corresponding to two selected values of probabilities of failure, is shown in Fig. 7. The $15 \%$ probability of failure is considered based on the proposed probability of shear failure for columns proposed by the ASCE/SEI 41-13 regulation [27]. It follows from Fig. 7(a), that the proposed equations result in drift ratios at $15 \%$ failure probability, which match well with the respective experimental results, whereas the drift capacities at $15 \%$ failure probability are generally overestimated by Elwood model and, at least partially, by the ASCE/SEI 41-13 regulation. In addition, the diagram for $50 \%$ probability of failure is depicted in Fig. 7(b) to highlight the probability of overestimating the 


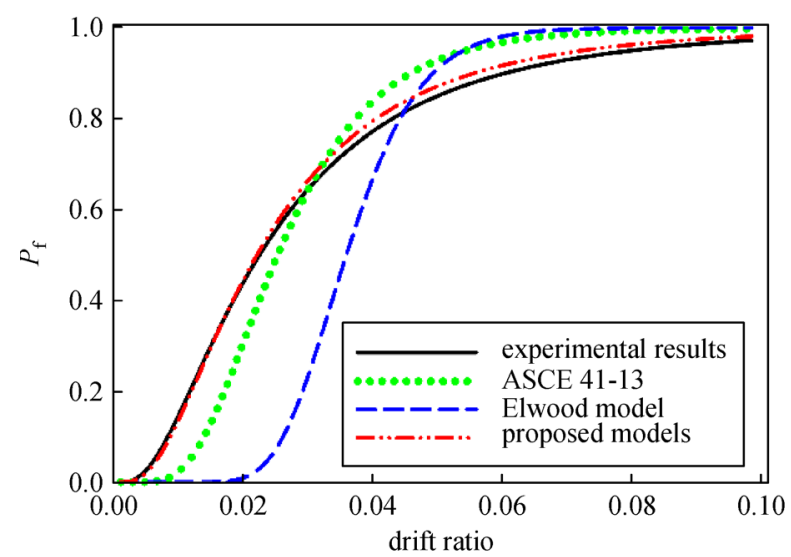

(a)

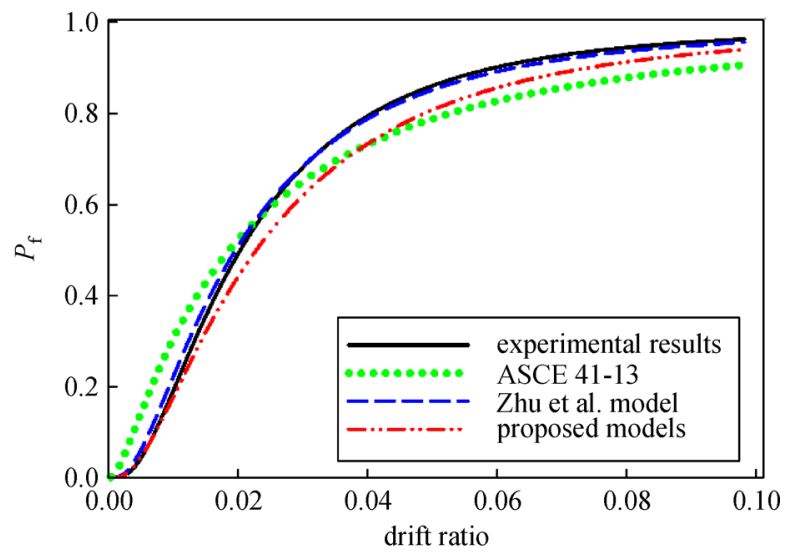

(b)

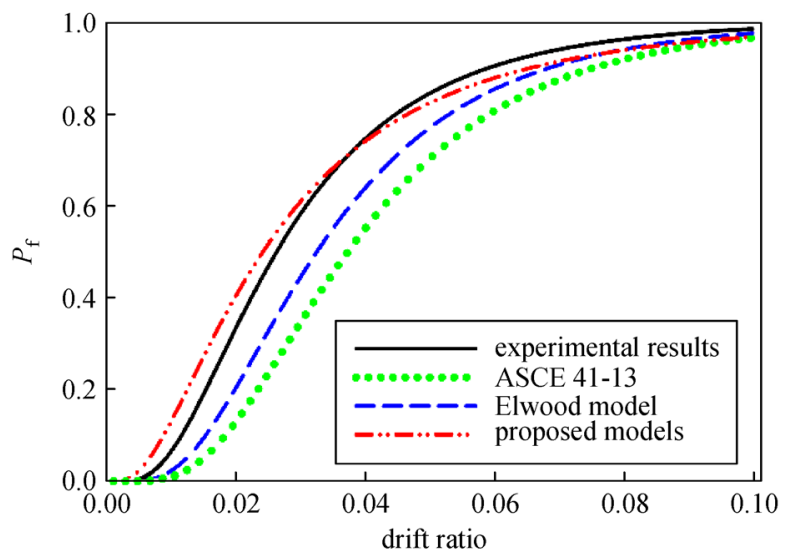

(c)

Fig. 6 Fragility curves corresponding to different failure modes. (a) Flexure-shear failure mode; (b) shear failure mode; (c) axial failure mode.

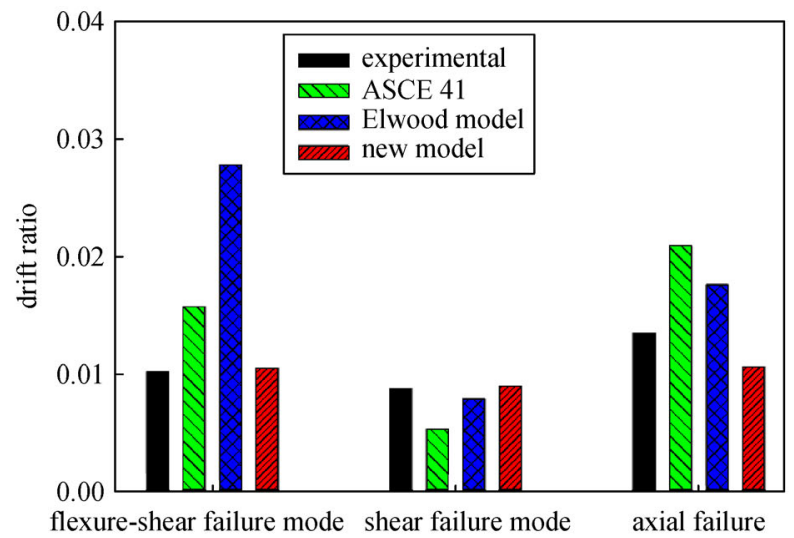

(a)

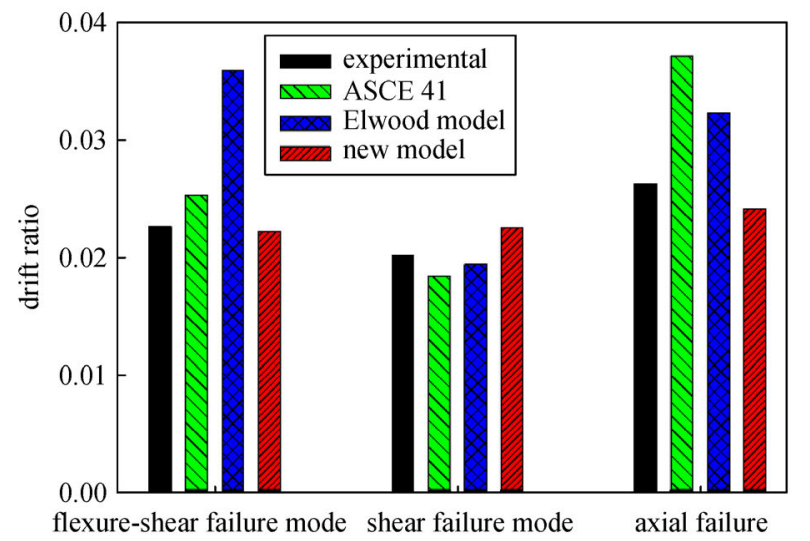

(b)

Fig. 7 Drift ratios corresponding to different probabilities of failure. (a) $15 \%$ probability of failure; (b) $50 \%$ probability of failure.

drift capacity by conventional approaches. Such unsafe structural global response predictions are also noticed in previous studies. For instance, $50 \%$ probability of exceeding proposed local thresholds at the component level are stated in the Turkish rehabilitation code for Life Safety (LS) and Collapse Prevention (CP). According to
Refs. [87,88] those performance levels correspond to $3.5 \%$ and $4.0 \%$ inter-story drift ratios, respectively. However, the specified values by the code are limited to $2.0 \%$ and $3.0 \%$ respectively for LS and CP performance objectives [89].

Finally, a performance function is defined as the ratio of 
observed to corresponding predicted drift capacity. Hence, values of the performance function smaller than one indicate an overestimation of the drift capacity and, thus, the respective region represents the failure zone of the performance function.

The fragility curves for this performance function are plotted in Fig. 8 for the different failure modes. The area under the fragility curves in the region with experimental to calculated drift ratio less than one can serve as indicator for each method to overestimate the actual drift capacity.

It follows from Fig. 8 that the probability of overestimating drift capacities is considerably less pronounced for the proposed model than for the models of the ASCE/ SEI 41-13 regulation and Elwood model, e.g., the probability of overestimating the drift capacity for the flexure-shear failure mode on the basis of Elwood model, the ASCE/SEI 41-13 regulation and the proposed approach are obtained from Fig. 8(a) as 0.78, 0.58, and 0.51, respectively. For the axial failure mode the respective probabilities are obtained from Fig. 8(c) as 0.59, 0.53, and 0.38 , respectively. However, the proposed model by Zhu

et al. presents slightly better performance for shear failure mode.

\section{Validation of the proposed model}

6.1 Validation of the proposed model for axial, flexure, and flexure-shear failure of RC columns

This subsection is devoted to the validation of the proposed models for flexural, shear failure (flexure-shear failure mode), and axial failure. To this end, a one-story and threebay RC frame with two ductile and two non-ductile columns on the scale of $1: 3$, tested on the shaking table by Wu et al. [90], is taken into account. The cracking patterns of the non-ductile column (denoted as $\mathrm{C} 1$ ) and ductile column (denoted as C4), including horizontal flexural and diagonal shear cracking, are shown in Figs. 9(a), 9(b), 9(d), and 9(e). It's worthwhile to mention that unlike the ductile column $\mathrm{C} 4$, the non-ductile column $\mathrm{C} 1$ experienced axial failure (shown in Figs. 9(c) and 9(f)) during the test [90].

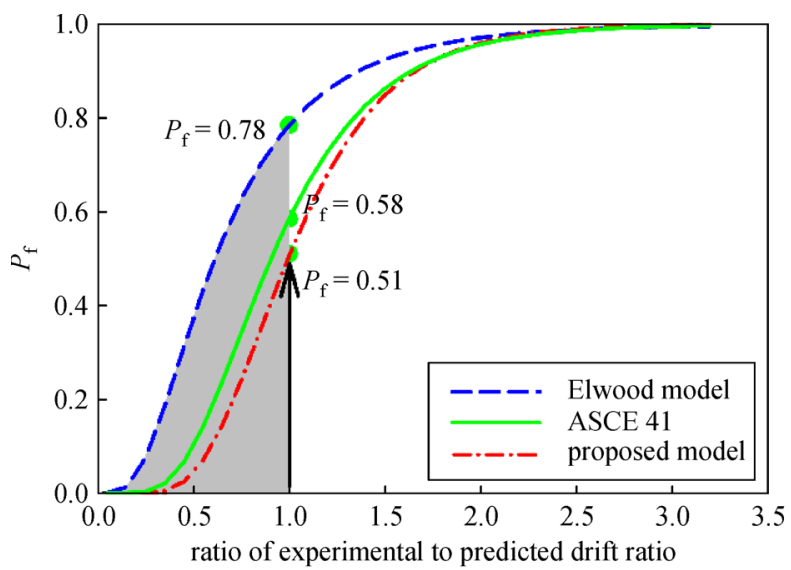

(a)

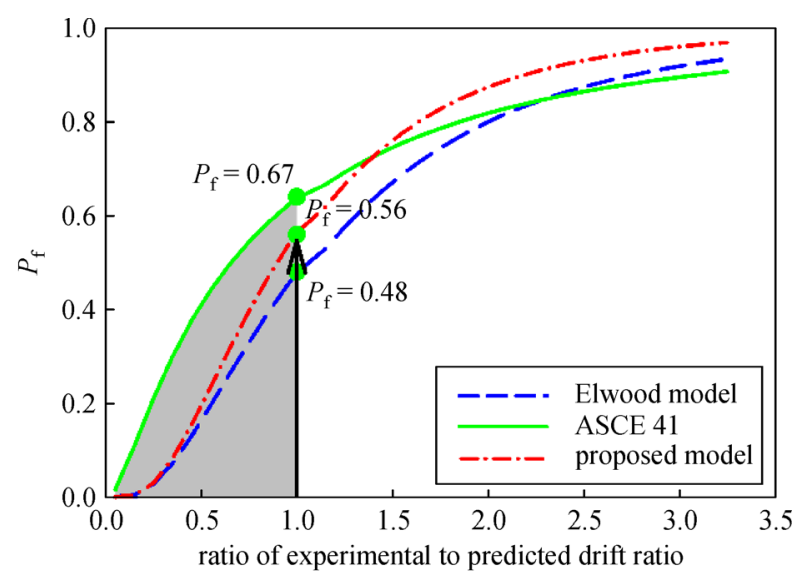

(b)

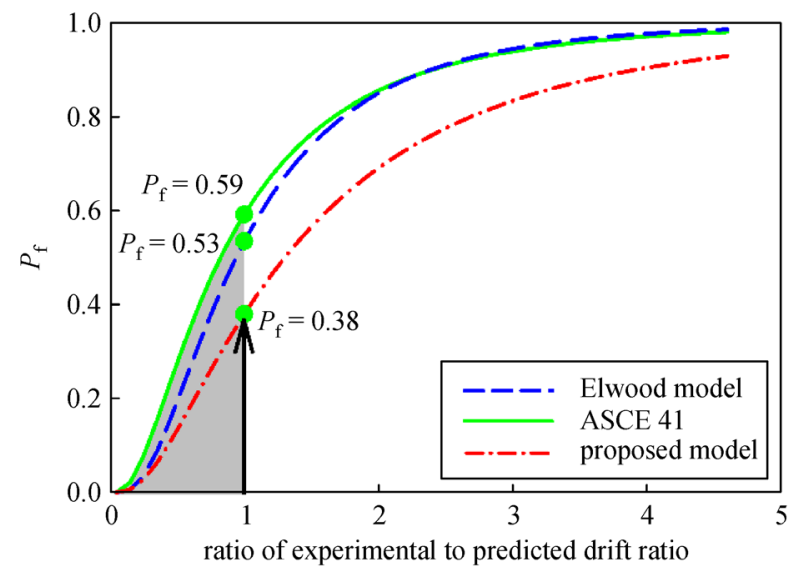

(c)

Fig. 8 Fragility curves for computing the probability of overestimating the drift capacities for different failure models by the proposed model, Elwood [25] and Zhu et al. [26] model and the ASCE/SEI 41-13 regulation. (a) Flexure-shear failure mode; (b) shear failure mode; (c) axial failure mode. 


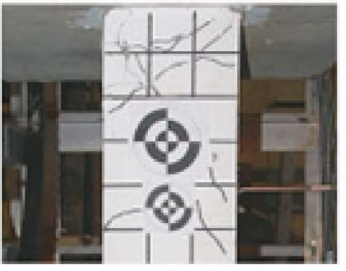

(a)

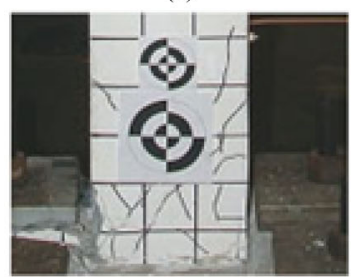

(b)

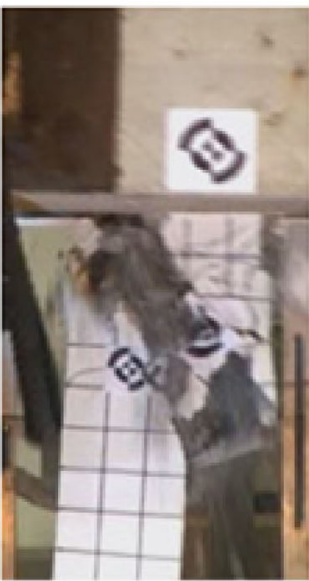

(c)

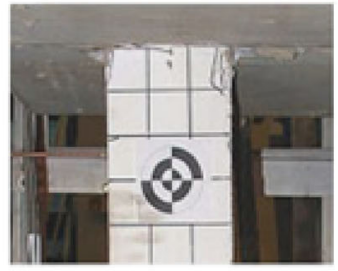

(d)

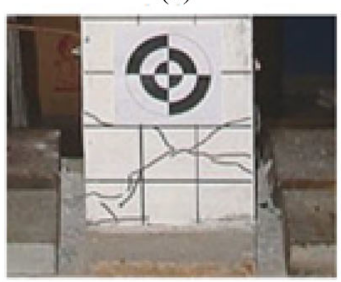

(e)

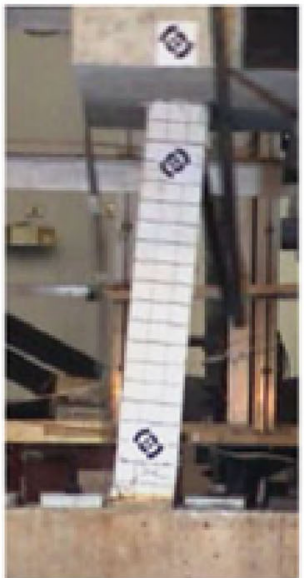

(f)

Fig. 9 Cracking patterns of non-ductile column C1: (a) top; (b) bottom; (c) axial failure at the top of C1 column. Cracking patterns of ductile columns C4: (d) top; (e) bottom and (f) at the lateral drift ratio of $9 \%$ [90].

Table 8 Mechanical and geometrical parameters of the tested columns [90]

\begin{tabular}{lcccc}
\hline column & $\left(\frac{\rho_{\mathrm{h}} f_{\mathrm{yt}}}{\rho_{\mathrm{l}} f_{\mathrm{yl}}}\right)$ & $\frac{P}{A_{\mathrm{g}} f_{\mathrm{c}}}$ & $\frac{a}{d}$ & $\frac{s}{d}$ \\
\hline $\mathrm{C} 1$ & 0.0918 & 0.10 & 3.759 & 0.751 \\
$\mathrm{C} 4$ & 1.587 & 0.10 & 3.759 & 0.248 \\
\hline
\end{tabular}

The mechanical and geometrical details for columns $\mathrm{C} 1$ and $\mathrm{C} 4$ are presented in Table 8 . In this table the distance from the maximum moment to the inflection point is given as $a=L / 2$ (for double curvature columns) with the column length $L=1000 \mathrm{~mm}$. The dimensions of the crosssections of both columns are $150 \mathrm{~mm} \times 150 \mathrm{~mm}$, the concrete cover is $17 \mathrm{~mm}$ and the stirrup spacing for the non-ductile and the ductile column is 100 and $33 \mathrm{~mm}$, respectively [90].

In the experimental test, the ratio $V_{\mathrm{p}} / V_{\mathrm{n}}$ for the nonductile and ductile columns was reported as 0.91 and 0.22 ,

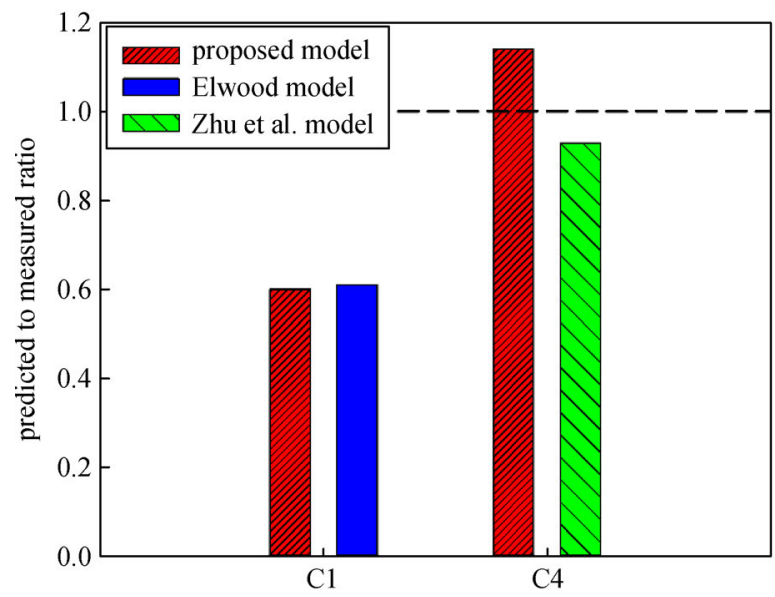

(a) respectively [90]. Hence, in this study, the failure mode for the non-ductile and ductile column is considered as flexure-shear and flexure, respectively, which is in compliance with the ASCE/SEI 41-13 concrete provisions [27]. The comparison between experimental results and the predicted ones by the proposed equations and Elwood [25] and Zhu et al. [26] model is illustrated in Fig. 10 in terms of the predicted results, normalized by the experimental results.

As can be seen in Fig. 10(a), for column C1 the proposed model is characterized by good agreement of the predicted

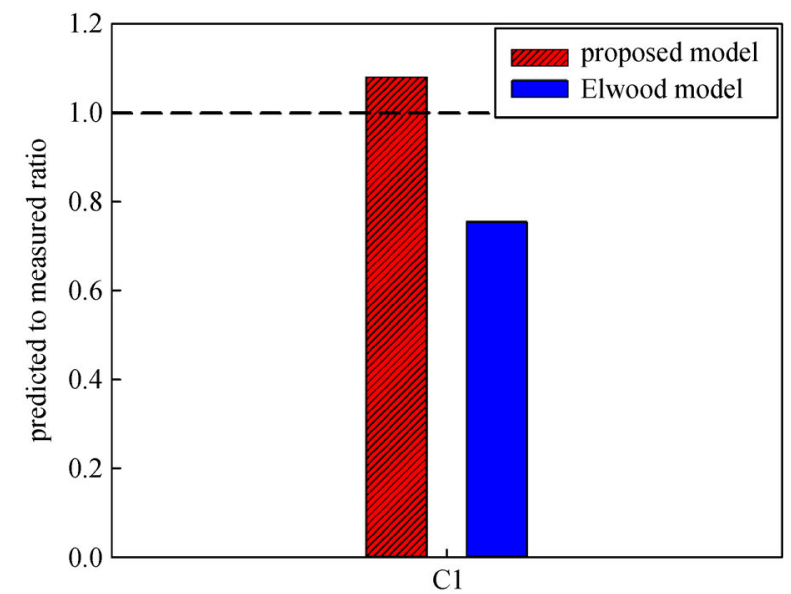

(b)

Fig. 10 Comparison of the predicted results by the proposed equations, Elwood and Zhu et al. models with experimental data by Wu et al. [90]. (a) Flexural and shear failure; (b) axial failure. 
drift ratio at flexure failure with the experimental result. However, it underestimates the drift ratio for the column $\mathrm{C} 1$ by about $40 \%$. It can be concluded from Fig. 10(b) that the proposed model appropriately predicts the drift ratio at axial failure. The ductile column (C4) is not included in Fig. 10(b), since it did not experience axial failure during the test.

6.2 Validation of the proposed models for axial and shear failure of RC columns

In this subsection the proposed models will be validated for axial failure and shear failure (shear failure mode). For this purpose three two-story and two-bay RC frames on the scale of 1:2.25, tested on the shaking table by Yavari et al. [91], are selected. The mechanical and geometrical details of the first columns experiencing shear and axial failure in the tested frames, are summarized in Table 9. In this experimental study, $a=L / 2$ with $L=1400 \mathrm{~mm}$. The dimensions of the cross-sections are $200 \mathrm{~mm} \times 200 \mathrm{~mm}$, the concrete cover is $17 \mathrm{~mm}$ and the stirrup spacing is 120 $\mathrm{mm}$ for all three tested frames [91].

The tested frames were designated based on Moderate (M) or High $(\mathrm{H})$ axial load in columns, Confined or Unconfined (C or $\mathrm{U}$ ) first story joints and Flexure-Shear (FS) failure mode in columns [91]. The observed cracking patterns (flexural and shear cracks) and failure of the three tested columns are shown in Figs. 11(a)-11(c). It was reported that all three columns of the tested frames experienced axial failure during the tests (shown in Figs. 11(d)-11(f)) [91].

In the experimental tests, the ratio $V_{\mathrm{p}} / V_{\mathrm{n}}$ for the columns in the three frames was reported slightly larger than one [91]. Hence, according to the ASCE/SEI 41-13 provisions [27], the failure mode of the columns in the three frames is considered as shear failure mode. Figure 12 depicts a comparison of the predicted results by the proposed equations and Elwood or Zhu et al. model, normalized by the experimental results.

It can be concluded from Fig. 12 that the results predicted by the proposed models are generally characterized by better agreement with the experimental data than the ones predicted by Elwood [25] and Zhu et al. model [26].

\section{Case study}

This section focuses on the assessment of the drift capacities of individual columns of two selected RC frames, as shown in Fig. 13, predicted by the proposed equations. The predictions are compared with the results of structural analyses of the two frames, based on the numerical modeling approach, proposed by Elwood and the ASCE/SEI 41-13 regulation.

Structural details of the RC frames are extracted from surveying existing buildings. They were proportioned such that the desired failure modes control the performance. For each frame, three different transverse reinforcement ratios are taken into account by varying the stirrup spacing (Fig. 13). Hence, actually six RC frames will be assessed.

The nonlinear 2D numerical structural analyses of the frames are carried out by means of the OpenSees software [92]. Since all surveyed buildings have one-way slabs, a

Table 9 Important mechanical and geometrical parameters of the selected columns of the tested frames [91]

\begin{tabular}{lllll}
\hline frame-column & $\left(\frac{\rho_{\mathrm{h}} f_{\mathrm{yt}}}{\rho_{\mathrm{f}} f_{\mathrm{yl}}}\right)$ & $\frac{P}{A_{\mathrm{g}} f_{\mathrm{c}}}$ & $\frac{a}{d}$ & $\frac{s}{d}$ \\
\hline MCFS-B1 & 0.0657 & 0.200 & 3.825 & 0.656 \\
HCFS-B1 & 0.0657 & 0.350 & 3.825 & 0.656 \\
MUFS-B2 & 0.0626 & 0.200 & 3.825 & 0.656 \\
\hline
\end{tabular}

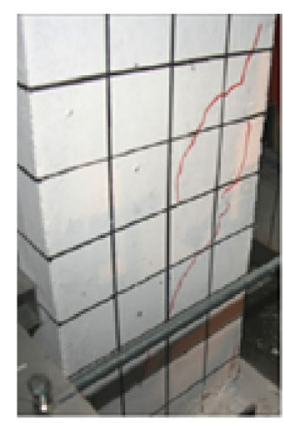

(a)

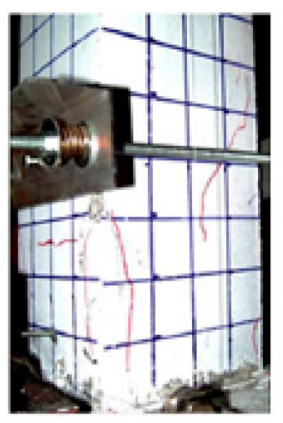

(b)

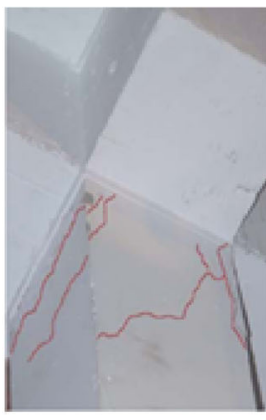

(c)

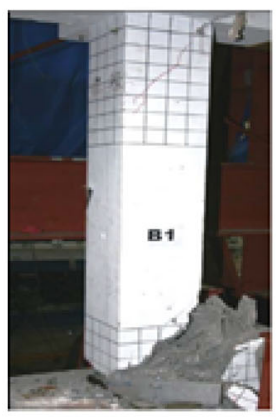

(d)

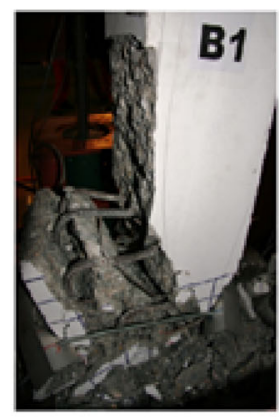

(e)

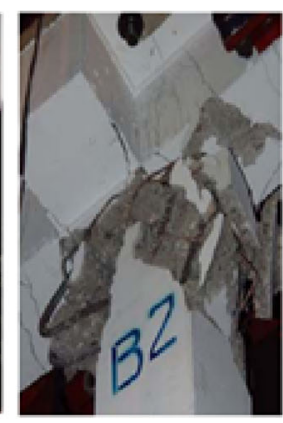

(f)

Fig. 11 Flexural and shear cracks in columns of the tested frames. (a) MCFS; (b) HCFS; (c) MUFS and failure of columns in the frames; (d) MCFS; (e) HCFS; (f) MUFS, according to Yavari [91]. 


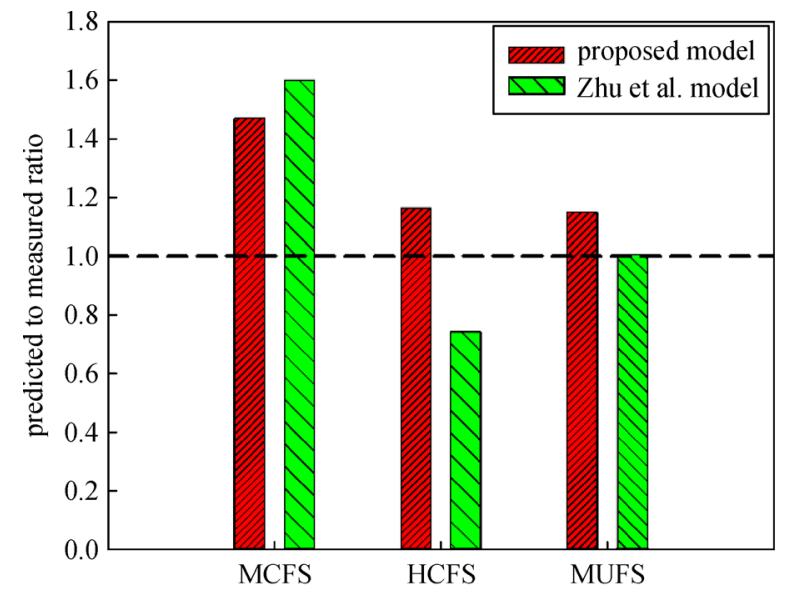

(a)

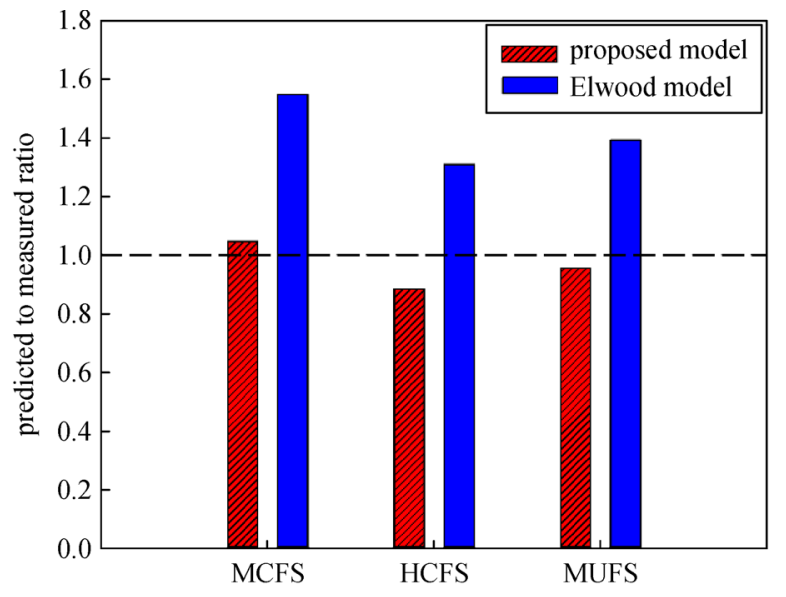

(b)

Fig. 12 Comparison of the predicted results by the proposed equations, Elwood and Zhu et al. models normalized by the experimental data by Yavari et al. [91]. (a) Shear failure; (b) axial failure.

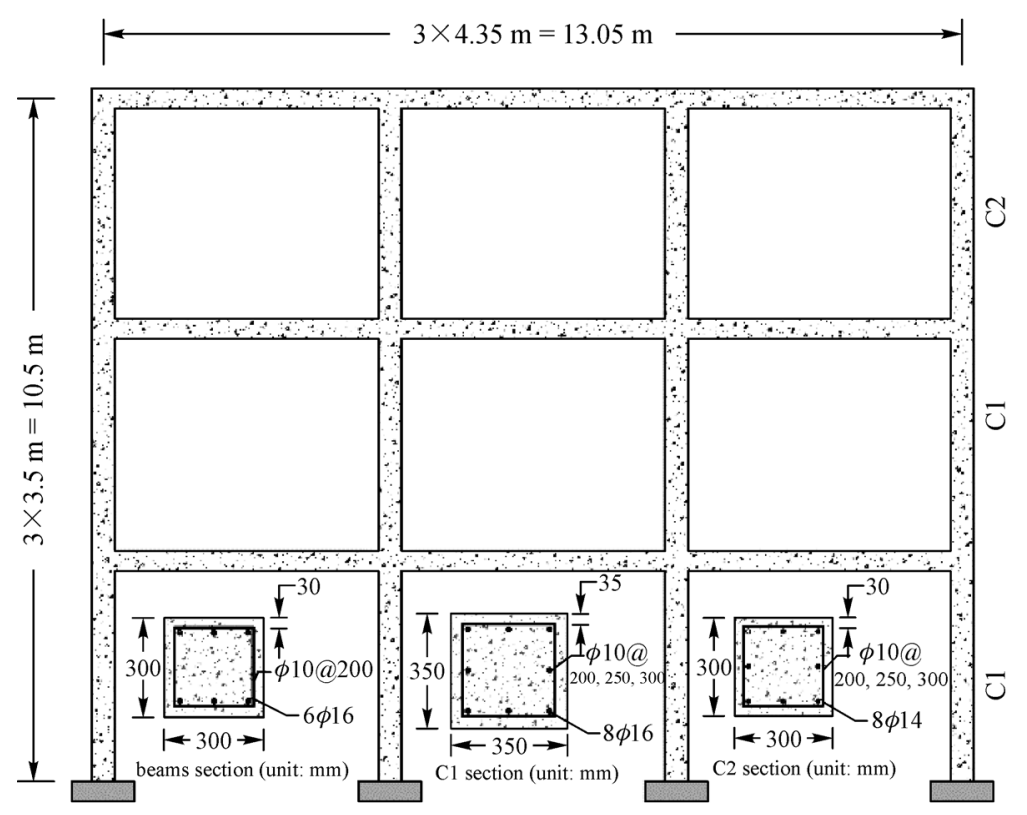

(a)

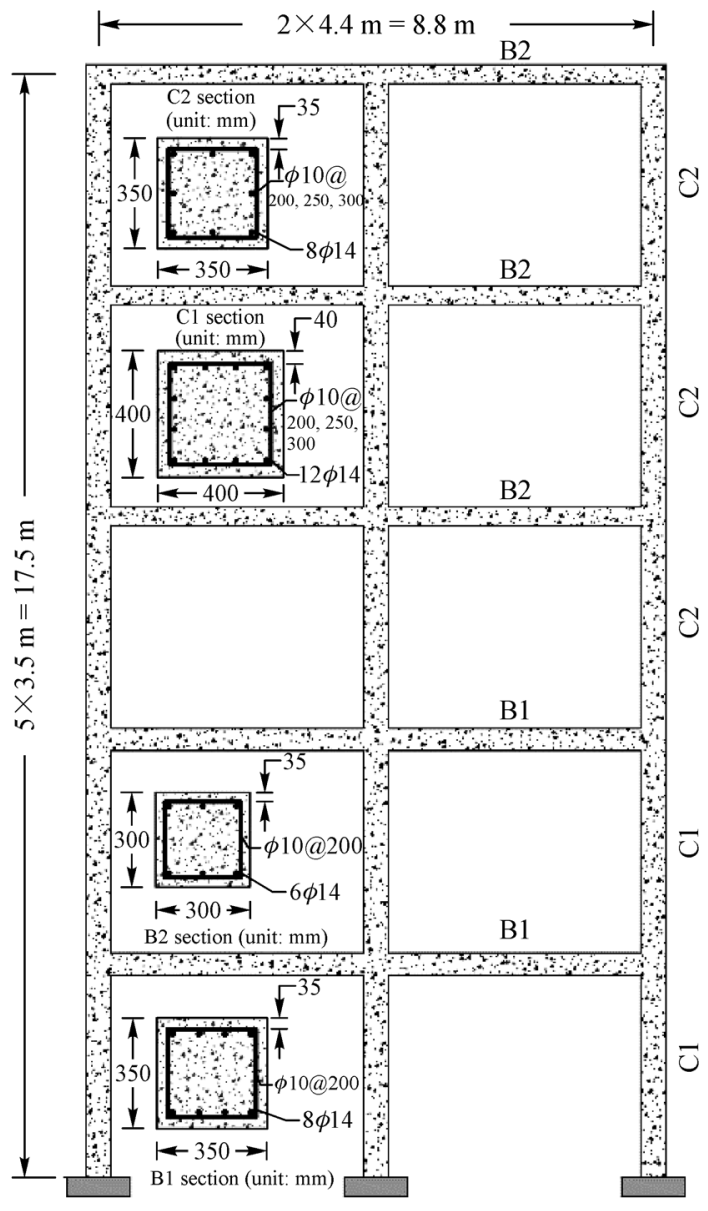

(b)

Fig. 13 Elevation view and structural details of the RC frames, selected for the case study. (a) 3-story frame; (b) 5-story frame.

distributed load (dead load plus $20 \%$ of the live load) resulting from the perpendicular direction is assigned to the beams. The assigned loads are specified based on reported values by professional companies particularly engaged in strengthening existing buildings. Additionally, masses were computed from aforementioned loads and self-weight 


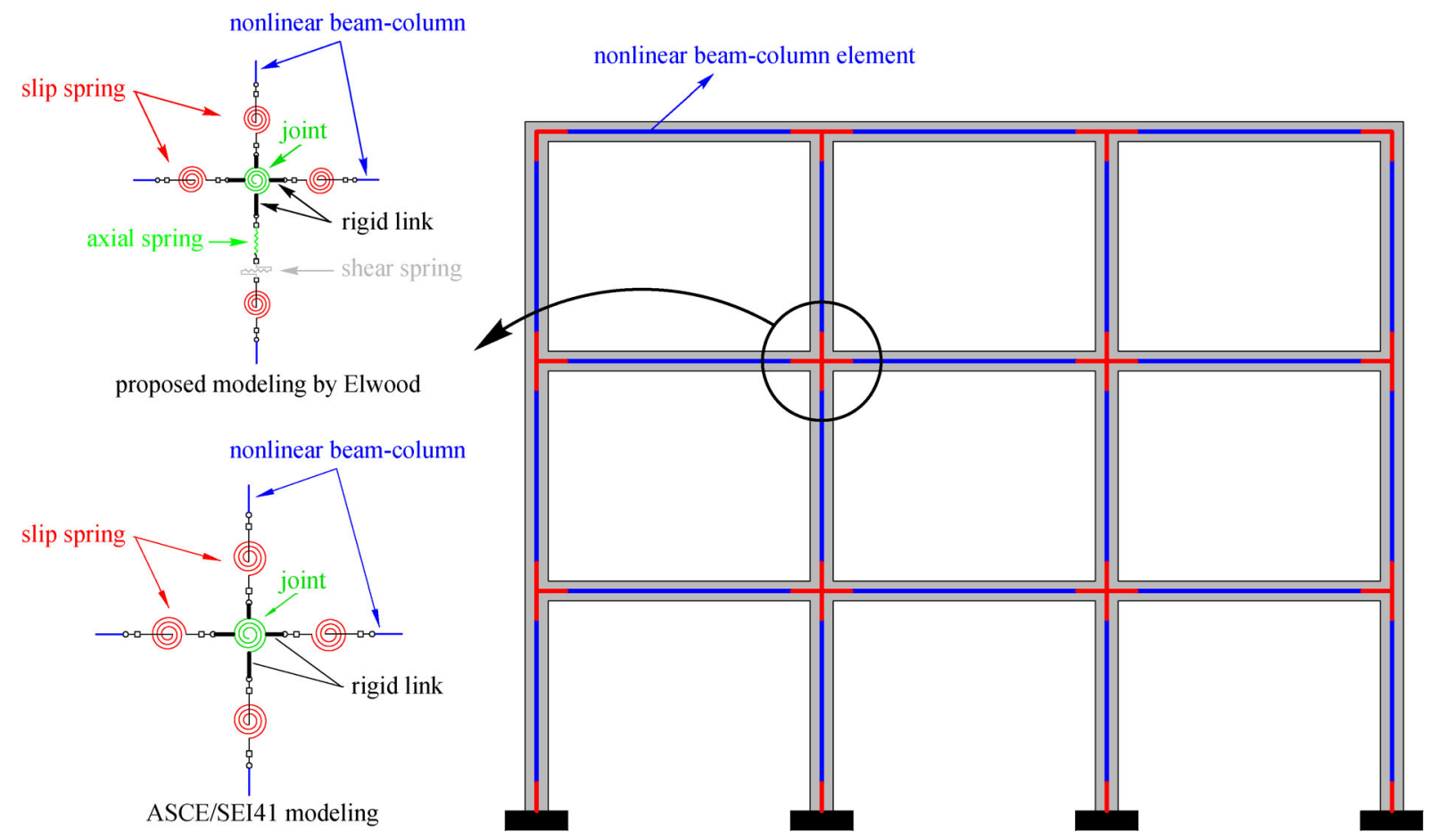

Fig. 14 Schematic view of the employed nonlinear structural models.

of the beams/columns, which are added as lumped masses to the nodes based on the respective tributary area. For the structural analyses the modeling approaches, proposed by Elwood [25] and the ASCE/SEI 41-13 regulation [27], are employed. They are characterized by introducing shear-, axial-, slip-, and joint-springs at the joints of the nonlinear beam-column elements. Full details of these elements can be found in $[92,93]$. A schematic view of the derived structural models and detailed views of the models at the joints are provided in Fig. 14.

The numerical analyses are conducted by performing Incremental Dynamic (IDA) and nonlinear static analyses, i.e., so-called pushover analyses. The latter are much easier to perform and are recommended in many regulations. It follows from previous studies that the responses, predicted by pushover analyses, acceptably match with those obtained from IDAs as the most accurate predicting tool; while the predicted damage location is not necessarily precise. In IDA, scaled ground motion records are individually applied until structural collapse is predicted. It was previously shown that different scaling methods (such as spectrum matching or codified one) may lead to different results [4,5]. Hence, to be consistent with conventional IDAs described in the literature, the applied ground motions are linearly scaled. Therefore, this analysis provides a broad knowledge about the structural behavior of the considered frames. In the present study, twelve records are selected from the database FEMA P695 [94]. They are all recorded from strong earthquake events by magnitudes greater than 6.5 . Since in all cases the source to recording station distance is greater than $10 \mathrm{~km}$, the selected records can be classified as far-field records. Moreover, their PGA and PGV vary in the range of 0.210 $0529 \mathrm{~g}$ and $16-59 \mathrm{~cm} / \mathrm{s}$, respectively. The $5 \%$ damped elastic spectrum of these ground motion records is shown in Fig. 15.

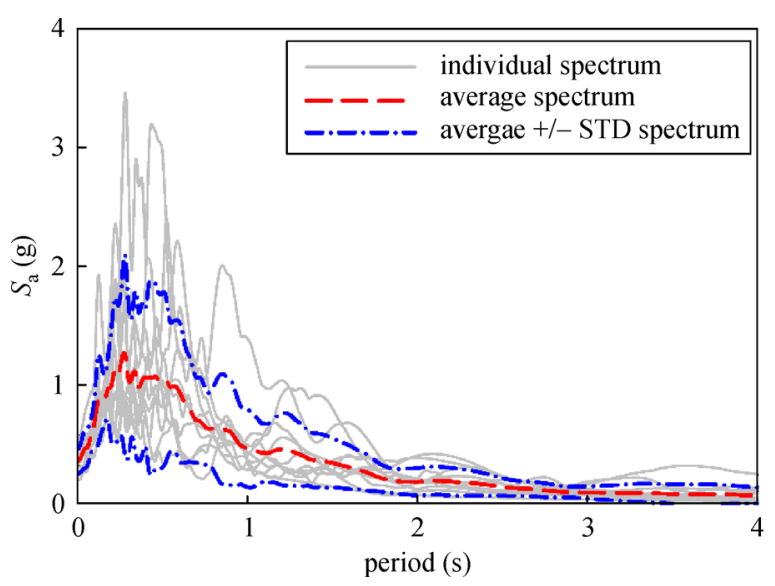

Fig. $155 \%$ damped elastic spectrum of assigned ground motion records.

Results of the IDAs, carried out on the basis of the two modeling approaches, are presented for both frames in Fig. 16. Maximum inter-story drifts, corresponding to different failure modes and initiation of dynamic instability, are highlighted for all considered ground motion 


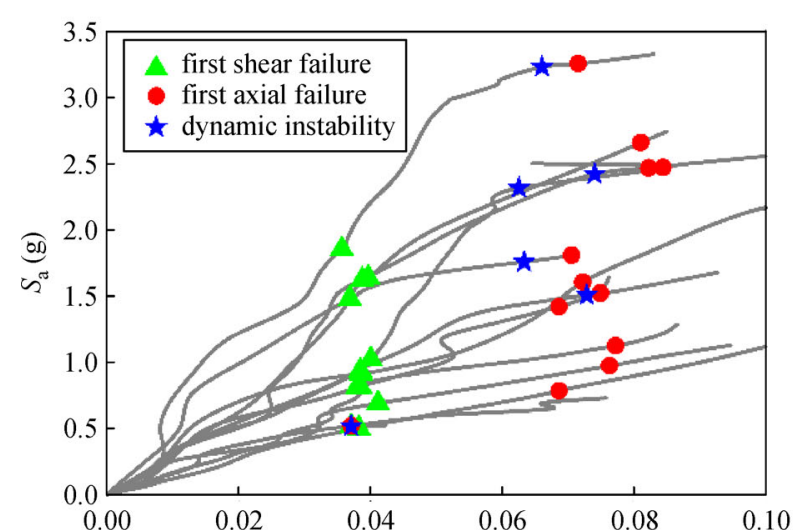

(a)

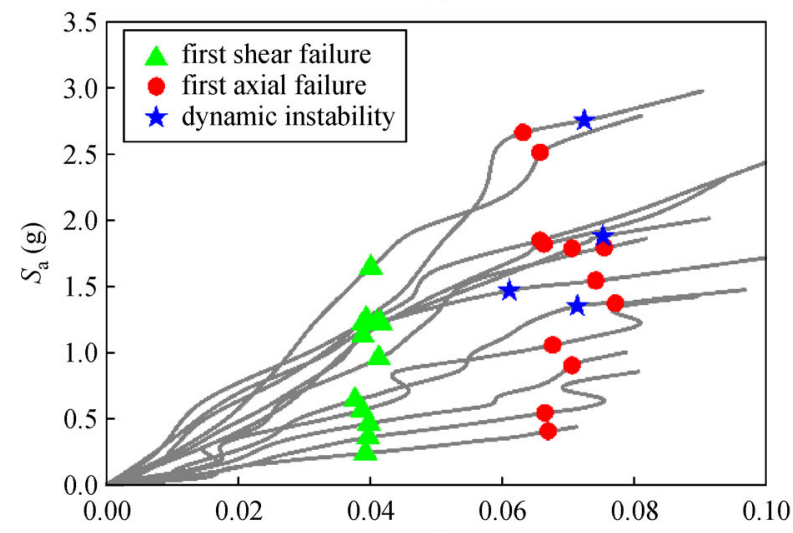

(c)

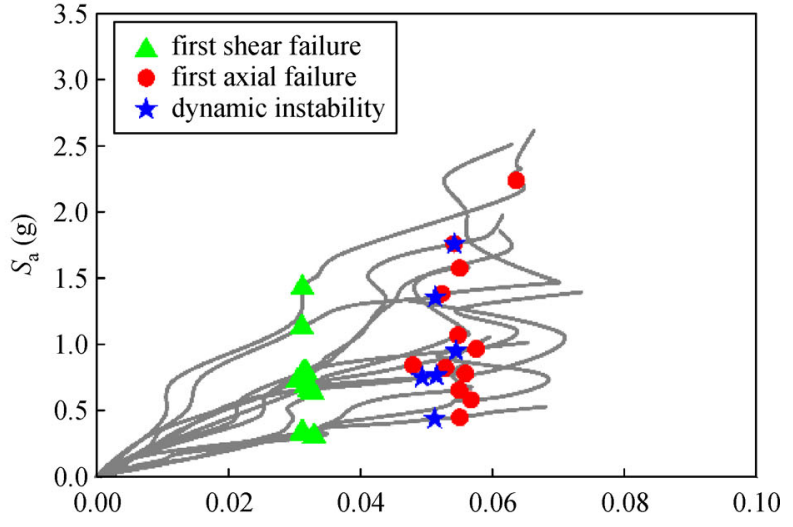

(b)

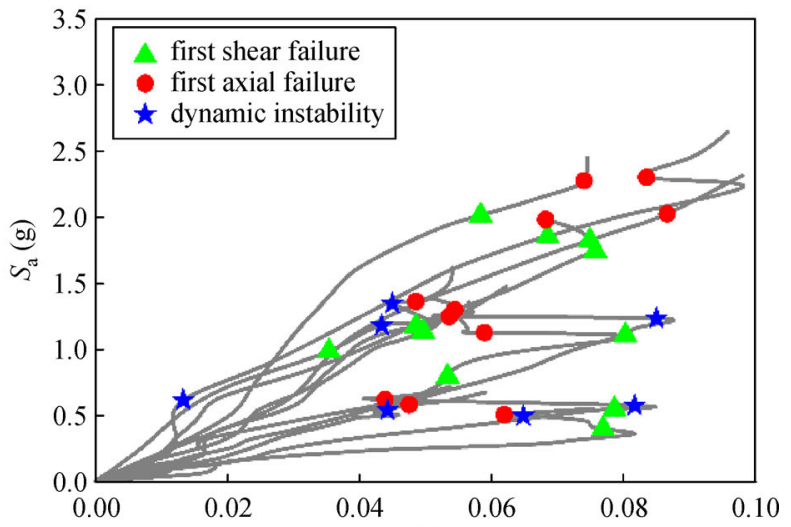

(d)

Fig. 16 IDA curves, obtained on the basis of the modeling approaches by Elwood and the ASCE/SEI 41-13 regulation, with the drift ratio capacities corresponding to different failure modes. (a) 3-story-ASCE method; (b) 3-story-Elwood method; (c) 5-story-ASCE method; (d) 5-story-Elwood method.

records. Global dynamic instability is defined as the point where a minor intensity increase causes a major increase of the drift ratio [95]. This state is out of scope of the present article.

The results of the pushover analyses, performed by

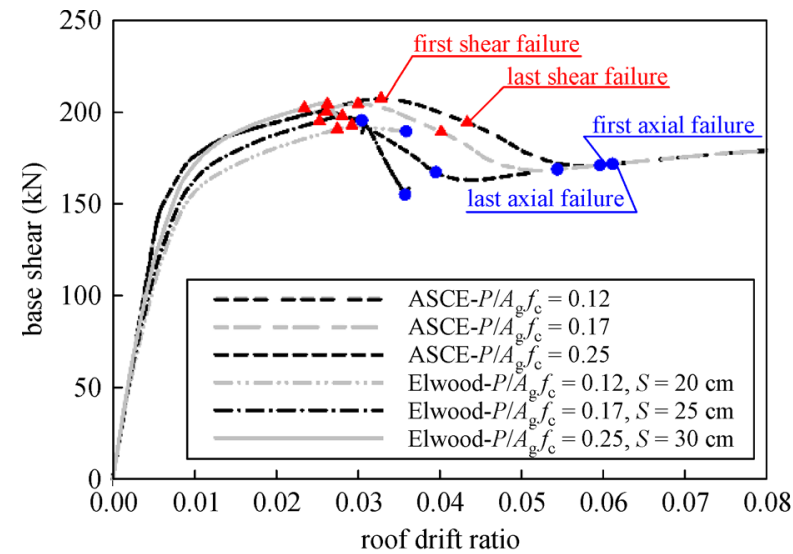

(a) subjecting the frames to the lateral load pattern based on the first mode of vibration, are presented in Fig. 17, depicting the predicted base shear in terms of the roof drift ratio.

Finally, the results for the drift ratios, determined from

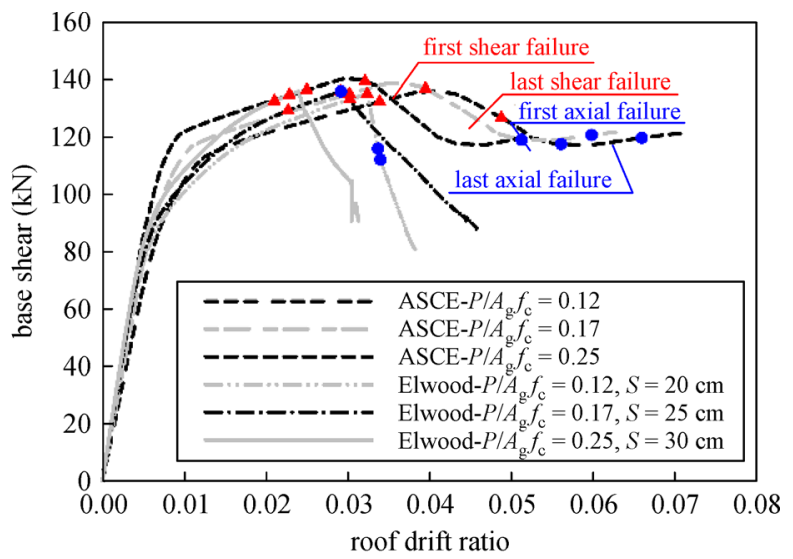

(b)

Fig. 17 Predicted base shear in terms of the roof drift obtained from pushover analyses and drift ratios corresponding to different failure modes, predicted on the basis of the ASCE regulation [27] and Elwood modeling approach [25]. (a) Shear failure; (b) axial failure. 


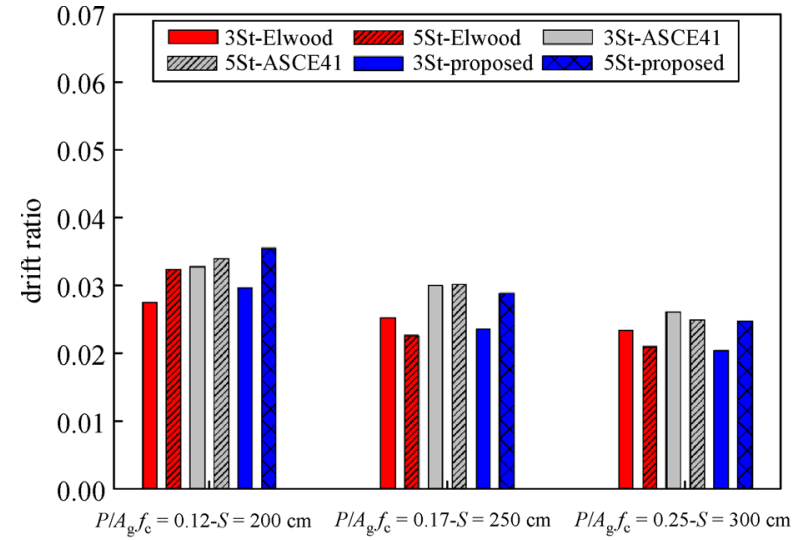

(a)

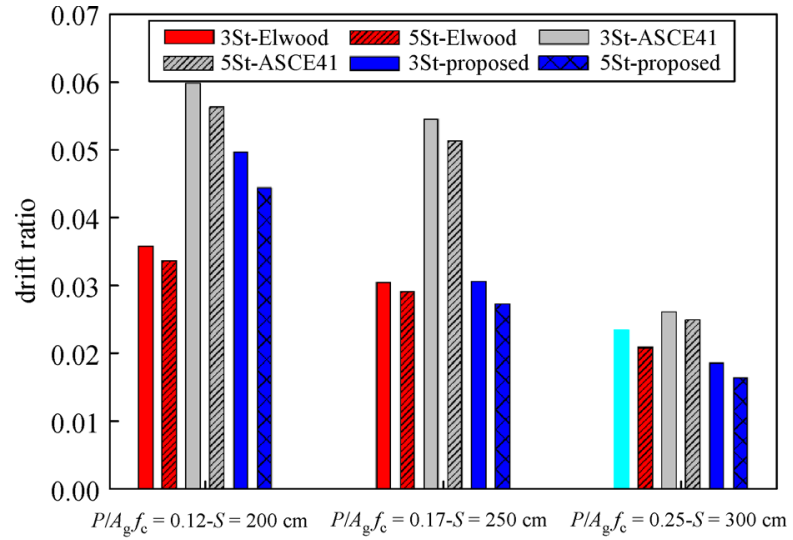

(b)

Fig. 18 Drift ratios predicted by the pushover analyses, based on the proposed equations for both shear and axial failure types and the modeling approaches by Elwood [25] and the ASCE regulation [27]. (a) Shear failure; (b) axial failure.

the pushover analyses and the proposed equations, are summarized in Fig. 18. They are classified based on the number of stories ( 3 or 5$)$, the axial load ratio $\left(P /\left(A_{\mathrm{g}} f_{\mathrm{c}}\right)=\right.$ $0.12,0.17,0.25)$, the transverse reinforcement detailing $(\mathrm{s}=20,35,30 \mathrm{~cm})$ and the failure type, i.e., shear or axial. As a general conclusion from the pushover analyses, by increasing the number of stories the drift ratio capacity is reduced, while the modeling approaches, proposed by Elwood and the ASCE/SEI 41-13 regulation seem to be less sensitive to this parameter. Furthermore, the ASCE approach predicts the largest drift capacities. Eventually, expectedly increasing the axial load ratio and spacing between transverse reinforcement bars causes the drift ratio capacity to be reduced.

\section{Summary and conclusions}

In this article, at first a comprehensive database for RC columns was presented, which includes 196 experiments for column failure in flexure and shear, which the latter is further categorized into two failure mode subsets, i.e., flexure-shear and shear, and 50 experiments for column failure in the axial failure mode.

On the basis of the experimental results, collected in the database, new empirical models were proposed for predicting the occurrence of flexural, shear, and axial failure in reinforced concrete columns. This objective was achieved by conducting variety of regression analyses (including linear, nonlinear, and nonparametric ones), evaluating the significance of different parameters and proposing straightforward equations which represent the corresponding capacity in terms of the drift ratio. The results, predicted by the proposed empirical models, were compared with experimental results and other conventional approaches, available in the literature. It was shown that the proposed equations predict drift capacities, which are in better agreement with experimental results than those computed by previously published models. In addition, the reliability of the proposed equations is higher from a probabilistic point of view. This is reflected by the fact that by the proposed equations drift capacities are less likely to be overestimated.

Open Access This article is licensed under a Creative Commons Attribution 4.0 International License, which permits use, sharing, adaptation, distribution and reproduction in any medium or format, as long as you give appropriate credit to the original author(s) and the source, provide a link to the Creative Commons licence, and indicate if changes were made.

The images or other third party material in this article areincluded in the article's Creative Commons licence, unless indicatedotherwise in a credit line to the material. If material is not includedin the article's Creative Commons licence and your intendeduse is not permitted by statutory regulation or exceeds the permitteduse, you will need to obtain permission directly from the copyrightholder.

To view a copy of this licence, visit http://creativecommons.org/licenses/ by $/ 4.0 /$.

Electronic Supplementary Material Supplementary material is available in the online version of this article at https://doi.org/10.1007/s11709-019$0554-2$ and is accessible for authorized users.

\section{References}

1. Allahvirdizadeh R, Rashetnia R, Dousti A, Shekarchi M. Application of polymer concrete in repair of concrete structures: A literature review. The 4th International Conference on Concrete Repair, Dresden, Germany, 2011

2. Ellingwood B R. Earthquake risk assessment of building structures. Reliability Engineering \& System Safety, 2001, 74(3): 251-262

3. Chao S H, Goel S C, Lee S S. A seismic design lateral force distribution based on inelastic state of structures. Earthquake Spectra, 2007, 23(3): 547-569

4. Allahvirdizadeh R, Khanmohammadi M, Marefat M S. Local and global design criteria in performance-based seismic design of new R.C buildings. The 4th International Conference on Seismic Retrofitting, Tabriz, Iran, 2013

5. Allahvirdizadeh R, Khanmohammadi M, Marefat M S. Investigat- 
ing effects of scaling and selecting earthquake ground motions on performance-based design of RC buildings. The 4th International Conference on Concrete \& Development, Tehran, Iran, 2013

6. Allahvirdizadeh R, Mohammadi M A. Upgrading equivalent static method of seismic designs to performance-based procedure. Journal of Earthquakes and Structures, 2016, 10(4): 849-865

7. Azadi Kakavand M R, Neuner M, Schreter M, Hofstetter G. A 3D continuum FE-model for predicting the nonlinear response and failure modes of RC frames in pushover analyses. Bulletin of Earthquake Engineering, 2018, 16(10): 4893-4917

8. Hamdia K M, Arafa M, Alqedra M. Structural damage assessment criteria for reinforced concrete buildings by using a Fuzzy Analytic Hierarchy Process. Underground Space, 2018, 3(3): 243-249

9. Farahmand H, Kakavand M R A, Tafreshi S T, Hafiz P H. The effect of mechanical and geometric parameters on the shear and axial failures of columns in reinforced concrete frames. Journal of Ciencia \& Natura, 2015, 37: 247-259

10. Shirmohammadi F, Esmaeily A. Performance of reinforced concrete columns under bi-axial lateral force/displacement and axial load. Journal of Engineering Structures, 2015, 99: 63-77

11. Choi K K, Truong G T, Kim J C. Seismic performance of lightly shear reinforced RC columns. Journal of Engineering Structures, 2016, 126: 490-504

12. Weng J, Lee C K, Tan K H, Lim N S. Damage assessment for reinforced concrete frames subject to progressive collapse. Journal of Engineering Structures, 2017, 149: 147-160

13. Witarto W, Lu L, Roberts R H, Mo Y L, Lu X. Shear-critical reinforced concrete columns under various loading rates. Frontiers of Structural and Civil Engineering, 2014, 8(4): 362-372

14. Sharifi Y, Maghsoudi A A. An experimental study on the flexural behavior of heavily steel reinforced beams with high-strength concrete. Frontiers of Structural and Civil Engineering, 2014, 8(1): $46-56$

15. Marí A, Cladera A, Bairán J, Oller E, Ribas C. Shear-flexural strength mechanical model for the design and assessment of reinforced concrete beams subjected to point or distributed loads. Frontiers of Structural and Civil Engineering, 2014, 8(4): 337-353

16. Adibi M, Marefat M S, Allahvirdizadeh R. Nonlinear modeling of cyclic response of RC beam-column joints reinforced by plain bars. Bulletin of Earthquake Engineering, 2018, 16(11): 5529-5556

17. Shing P B, Spencer B. Modeling of shear behavior of RC bridge structures. In: Modeling of Inelastic Behavior of RC Structures Under Seismic Load. American Society of Civil Engineers, 2001, 315-333

18. Ozbolt J, Mayer U, Vocke H. Smeared fracture FE-analysis of reinforced concrete structures - theory and examples. In: Modeling of Inelastic Behavior of RC Structures Under Seismic Load. American Society of Civil Engineers, 2001, 234-256

19. Kaneko Y, Mihashi H, Ishihara S. Entire load-displacement characteristics for direct shear failure of concrete. In: Modeling of Inelastic Behavior of RC Structures Under Seismic Load. American Society of Civil Engineers, 2001, 175-192

20. Kato D, Ohnishi K. Axial load carrying capacity of reinforced concrete columns under lateral load reversals. In: Proceedings of the Third US-Japan Workshop on Performance-Based Earthquake Engineering Methodology for Reinforced Concrete Building
Structures, 2002, 247-255

21. Sezen H. Seismic Response and Modeling of Reinforced Concrete Building Columns. Dissertation for the Doctoral Degree. Berkeley: University of California, 2002

22. Pujol S, Ramirez J A, Sozen M A. Drift capacity of reinforced concrete columns subjected to cyclic shear reversals. Seismic response of concrete bridges, Special Publication. American Concrete Institute, 1999, 187: 255-274

23. Pujol S, Sozen M, Ramírez J A. Transverse reinforcement for columns of frames to resist earthquakes. Journal of Structural Engineering, 2000, 126(4): 461-466

24. Pincheira J A, Dotiwala F S, D'Souza J T. Seismic analysis of older reinforced concrete columns. Earthquake Spectra, 1999, 15(2): 245272

25. Elwood K J. Shake table tests and analytical studies on the gravity load collapse of reinforced concrete frames. Dissertation for the Doctoral Degree. Berkeley: University of California, 2002

26. Zhu L, Elwood K J, Haukaas T. Classification and seismic safety evaluation of existing reinforced concrete columns. Journal of Structural Engineering, 2007, 133(9): 1316-1330

27. ASCE/SEI 41. Seismic Rehabilitation of Existing Buildings. American Society of Civil Engineers, Reston, Virginia, USA, 2013

28. Thanh Ngoc Tran C, Li B. Ultimate displacement of reinforced concrete columns with light transverse reinforcement. Journal of Earthquake Engineering, 2013, 17(2): 282-300

29. Aboutaha R S, Engelhardt M D, Jirsa J O, Kreger M E. Rehabilitation of shear critical concrete columns by use of rectangular steel jackets. ACI Structural Journal, 1999, 90(1): 68-78

30. Arakawa T, Arai Y, Mizoguchi M, Yoshida M. Shear resisting behavior of short reinforced concrete columns under biaxial bending-shear and varying axial load. Transactions of the Japan Concrete Institute, 1990, 12: 347-354

31. Atalay M B, Penzien J. The seismic behavior of critical regions of reinforced concrete components as influenced by moment, shear and axial force. University of California, Berkeley, California, 1975

32. Azizinamini A, Johal L S, Hanson N W, Corley W G. Effects of transverse reinforcement on seismic performance of columns - A partial parametric investigation. Project No. CR-9617, Construction Technology Laboratories, Skokie, Illinois, 1988

33. Bayrak O, Sheikh S. Design of rectangular HSC columns for ductility. Special Publication, American Concrete Institute, 2003, 61-82

34. Bechtoula H, Kono S, Watanabe F. Experimental and analytical investigations of seismic performance of cantilever reinforced concrete columns under varying transverse and axial loads. Journal of Asian Architecture and Building Engineering, 2005, 4(2): 467474

35. Esaki F. Reinforcing effect of steel plate hoops on ductility of reinforced concrete square column. In: The 11th World Conference on Earthquake Engineering, Pergamon, Turkey, 1996

36. Henkhaus K W. Axial failure of vulnerable reinforced concrete columns damaged by shear reversals. Dissertation for the Doctoral Degree. Indiana: Purdue University, 2010

37. Ikeda A. Experimental Studies on Load-Deflection Characteristics of Reinforced Concrete Columns Subjected to Alternate Loading. Report of the Training Institute for Engineering Teachers, 
Yokohama National University, Kanagawa, Japan, 1968

38. Imai H S, Yamamoto Y A. Study on causes of earthquake damage of Izumi high school due to Miyagi-Ken-Oki earthquake in 1978. Transactions of the Japan Concrete Institute, 1986, 8: 405-418

39. Iwasaki T, Kawasima K, Hagiwara R, Koyama T, Yoshida T. Experimental investigation on hysteretic behavior of reinforce concrete bridge pier columns. In: The 17th Joint Meeting of U.S.Japan Panel on Wing and Seismic Effects, Public Works Research Institute, Ministry of Construction, Japan, 1985

40. Kabeyasawa T, Tasai A, Igarashi S. Test and analysis of reinforced concrete columns strengthened with polyester sheet. In: 13th World Conference on Earthquake Engineering, Vancouver, British Columbia, Canada, 2004

41. Kanda M, Shirai N, Adachi H, Sato T. Analytical study on elastoplastic hysteretic behaviors of reinforced concrete members. Transactions of the Japan Concrete Institute, 1988, 10: 257-264

42. Kokusho S. A List of Past Experimental Results of Reinforced Concrete Columns. Building Research Institute, Ministry of Construction, 1964

43. Kokusho S, Fukuhara M. A List of Past Experimental Results of Reinforced Concrete Columns. Building Research Institute, Ministry of Construction, 1965

44. Li X, Park R, Tanaka H. Effects of variations in axial load level on the strength and ductility of reinforced concrete columns. In: Pacific Conference on Earthquake Engineering, Auckland, New Zealand, 1991

45. Lynn A C. Seismic evaluation of existing reinforced concrete building columns. Dissertation for the Doctoral Degree. Berkeley: University of California, 2001

46. Matamoros A B. Study of drift limits for high-strength concrete columns. Dissertation for the Doctoral Degree. Illinois: University of Illinois at Urbana-Champaign, 1999

47. Matchulat L. Mitigation of collapse risk in vulnerable concrete buildings. Thesis for the Master's Degree. Kansas: University of Kansas, 2008

48. Mo Y, Wang S J. Seismic behavior of RC columns with various tie configurations. Journal of Structural Engineering, 2000, 126(10): $1122-1130$

49. Nagasaka T. Effectiveness of steel fiber as web reinforcement in reinforced concrete columns. Transactions of the Japan Concrete Institute, 1982, 4: 493-500

50. Nakamura T, Yoshimura M. Gravity load collapse of reinforced concrete columns with brittle failure modes. Journal of Asian Architecture and Building Engineering, 2002, 1(1): 21-27

51. Nakamura T, Yoshimura M. Simulation of old reinforced concrete column collapse by pseudo-dynamic test method. In: The 15th World Conference on Earthquake Engineering, Lisbon, Portugal, 2012

52. Ohno T, Nishioka T. An experimental study on energy absorption capacity of columns in reinforced concrete structures. Japan Society of Civil Engineers, 1984, 1(2): 137-147

53. Ohue M, Morimoto H, Fujii S, Morita S. The behavior of R.C. short columns failing in splitting bond-shear under dynamic lateral loading. Transactions of the Japan Concrete Institute, 1985, 7: 293300

54. Ono A, Shirai N, Adachi H, Sakamaki Y. Elasto-plastic behavior of reinforced concrete column with fluctuating axial force. Transactions of the Japan Concrete Institute, 1989, 11: 239-246

55. Ousalem H, Kabeyasawa T, Tasai A. Evaluation of ultimate deformation capacity at axial load collapse of reinforced concrete columns. In: The 13th World Conference on Earthquake Engineering,Vancouver, Canada, 2004

56. Priestley M J N, Verma R, Xiao Y. Seismic shear strength of reinforced concrete columns. Journal of Structural Engineering, 1994, 120(8): 2310-2329

57. Ramirez H, Jirsa J O. Effect of Axial Load on Shear Behavior of Short RC Columns Under Cyclic Lateral Deformations. Report on a Research Project, Department of Civil Engineering, University of Texas at Austin, Austin, Texas, 1980

58. Saatcioglu M, Grira M. Confinement of reinforced concrete columns with welded reinforcement grids. ACI Structural Journal, 1999, 96(1): 29-39

59. Saatcioglu M, Ozcebe G. Response of reinforced concrete columns to simulated seismic loading. ACI Structural Journal, 1989, 86(1): $3-12$

60. Soesianawati M T. Limited ductility design of reinforced concrete columns. Thesis for the Master's Degree. Christchurch: University of Canterbury, 1986

61. Takemura H, Kawashima K. Effect of loading hysteresis on ductility capacity of bridge piers. Journal of Structural Engineering, 1997, 43: 849-858

62. Tanaka H. Effect of lateral confining reinforcement on the ductile behavior of reinforced concrete columns. Dissertation for the Doctoral Degree. Christchurch: University of Canterbury, 1990

63. Umehara H, Jirsa J O. Shear Strength and Deterioration of Short Reinforced Concrete Columns Under Cyclic Deformations. Report on a Research Project, Department of Civil Engineering, University of Texas at Austin, Austin, Texas, 1982

64. Umemura H, Endo T. A List of Past Experimental Results of Reinforced Concrete Columns. Building Research Institute, Ministry of Construction. Japan, 1970

65. Watson S. Design of reinforced concrete frames of limited ductility. Dissertation for the Doctoral Degree. Christchurch: University of Canterbury, 1989

66. Wehbe N, Saiidi M S, Sanders D. Confinement of rectangular bridge columns for moderate seismic areas. National Center for Earthquake Engineering Research (NCEER), 1998, 12(1): 397-406

67. Wibowo A, Wilson J L, Lam N T K, Gad E F, Fardipour M, Rodsin K, Lukkunaprasit P. Drift capacity of lightly reinforced concrete columns. Australian Earthquake Engineering Society Conference, Perth, Western Australia, 2010

68. Wight J K, Sozen M A. Shear Strength Decay in Reinforced Concrete Columns Subjected to Large Deflection Reversals. Technical Report, University of Illinois, Urbana, Champaign, 1973

69. Yalcin C. Seismic Evaluation and retrofitting of existing reinforced concrete bridge columns. Dissertation for the Doctoral Degree. Ontario: University of Ottawa, Ottawa, 1997

70. Yoshimura M, Takaine Y, Nakamura T. Axial collapse of reinforced concrete columns. In: The 13th World Conference on Earthquake Engineering, Vancouver, British Columbia, Canada, 2004

71. Zahn F A. Design of reinforced bridge columns for strength and ductility. Dissertation for the Doctoral Degree. Christchurch: 
University of Canterbury, 1985

72. Zhou X S, Satoh T, Jiang W S, Ono A, Shimizu Y. Behavior of reinforced concrete short column under high axial load. Transactions of the Japan Concrete Institute, 1987, 9: 541-548

73. Pujol S. Drift capacity of reinforced concrete columns subjected to displacement reversals. Dissertation for the Doctoral Degree. Indiana: Purdue University, 2002

74. SPSS. IBM SPSS Statistics for Windows. Version 24.0. Armonk, NY: IBM Corp, 2016

75. MATLAB and Statistics Toolbox Release. Natick, Massachusetts: The MathWorks, Inc., 2018

76. Badawy M F, Msekh M A, Hamdia K M, Steiner M K, Lahmer T, Rabczuk T. Hybrid nonlinear surrogate models for fracture behavior of polymeric nanocomposites. Probabilistic Engineering Mechanics, 2017, 50: 64-75

77. Hamdia K M, Ghasemi H, Zhuang X, Alajlan N, Rabczuk T. Sensitivity and uncertainty analysis for flexoelectric nanostructures. Computer Methods in Applied Mechanics and Engineering, 2018, 337: 95-109

78. Hamdia K M, Silani M, Zhuang X, He P, Rabczuk T. Stochastic analysis of the fracture toughness of polymeric nanoparticle composites using polynomial chaos expansions. International Journal of Fracture, 2017, 206(2): 215-227

79. Vu-Bac N, Lahmer T, Keitel H, Zhao J, Zhuang X, Rabczuk T. Stochastic predictions of bulk properties of amorphous polyethylene based on molecular dynamics simulations. Mechanics of Materials, 2014, 68: 70-84

80. Vu-Bac N, Lahmer T, Zhang Y, Zhuang X, Rabczuk T. Stochastic predictions of interfacial characteristic of polymeric nanocomposites (PNCs). Composites. Part B, Engineering, 2014, 59: 80-95

81. Vu-Bac N, Lahmer T, Zhuang X, Nguyen-Thoi T, Rabczuk T. A software framework for probabilistic sensitivity analysis for computationally expensive models. Advances in Engineering Software, 2016, 100: 19-31

82. Vu-Bac N, Silani M, Lahmer T, Zhuang X, Rabczuk T. A unified framework for stochastic predictions of mechanical properties of polymeric nanocomposites. Computational Materials Science, 2015, 96: 520-535

83. Vu-Bac N, Rafiee R, Zhuang X, Lahmer T, Rabczuk T. Uncertainty quantification for multiscale modeling of polymer nanocomposites with correlated parameters. Composites. Part B, Engineering, 2015, 68: 446-464

84. Kim J H, Mander J B. Truss Modeling of Reinforced Concrete Shear-Flexure Behavior. Multidisciplinary Center for Earthquake Engineering Research, University of Buffalo, Buffalo, New York, 1999

85. Nowak A S, Collins K R. Reliability of Structures. London: CRC Press, 2012

86. Mai C, Konakli K, Sudret B. Seismic fragility curves for structures using non-parametric representations. Frontiers of Structural and Civil Engineering, 2017, 11(2): 169-186

87. Allahvirdizadeh R, Gholipour Y. Reliability evaluation of predicted structural performances using nonlinear static analysis. Bulletin of Earthquake Engineering, 2017, 15(5): 2129-2148

88. Allahvirdizadeh R, Khanmohammadi M, Marefat M S. Probabilistic comparative investigation on introduced performance-based seismic design and assessment criteria. Engineering Structures, 2017, 151: 206-220

89. Sucuoğlu H. The Turkish seismic rehabilitation code. In: Proceedings of the 1st European Conference on Earthquake Engineering and Seismology, Geneva, Switzerland, 2006, 1699-1708

90. Wu C L, Kuo W W, Yang Y S, Hwang S J, Elwood K J, Loh C H, Moehle J P. Collapse of a nonductile concrete frame: Shaking table tests. Earthquake Engineering \& Structural Dynamics, 2009, 38(2): 205-224

91. Yavari S. Shaking table tests on the response of reinforced concrete frames with non-seismic detailing. Dissertation for the Doctoral Degree. Vancouver: University of British Columbia, 2011

92. McKenna F, Fenves G L, Scott M H. Open system for earthquake engineering simulation. Berkeley: University of California, 2002

93. Azadi Kakavand M R. Limit state material manual. 2012

94. FEMA (Federal Emergency Management Agency). Quantification of Building Seismic Performance Factors, FEMA P695. 2009

95. Azadi Kakavand M R, Khanmohammadi M. Seismic Fragility assessment of local and global failures in low-rise non-ductile existing RC buildings: Empirical shear-axial modelling vs. ASCE/ SEI 41 approach. Journal of Computational Engineering and Physical Modeling, 2018, 1(1): 38-57 